\title{
Review Article \\ International Standard Problems and Small Break Loss-of-Coolant Accident (SBLOCA)
}

\author{
N. Aksan \\ Paul Scherrer Institut (PSI), 5232 Villigen PSI, Switzerland \\ Correspondence should be addressed to N. Aksan, nusret.aksan@psi.ch
}

Received 8 May 2007; Accepted 13 December 2007

Recommended by Cesare Frepoli

Best-estimate thermal-hydraulic system codes are widely used to perform safety and licensing analyses of nuclear power plants and also used in the design of advance reactors. Evaluation of the capabilities and the performance of these codes can be accomplished by comparing the code predictions with measured experimental data obtained on different test facilities. OECD/NEA Committee on the Safety of Nuclear Installations (CSNI) has promoted, over the last twenty-nine years, some forty-eight international standard problems (ISPs). These ISPs were performed in different fields as in-vessel thermal-hydraulic behaviour, fuel behaviour under accident conditions, fission product release and transport, core/concrete interactions, hydrogen distribution and mixing, containment thermal-hydraulic behaviour. $80 \%$ of these ISPs were related to the working domain of principal working group no. 2 on coolant system behaviour (PWG2) and were one of the major PWG2 activities for many years. A global review and synthesis on the contribution that ISPs have made to address nuclear reactor safety issues was initiated by CSNI-PWG2 and an overview on the subject of small break LOCA ISPs is given in this paper based on a report prepared by a writing group. In addition, the relevance of small break LOCA in a PWR with relation to nuclear reactor safety and the reorientation of the reactor safety program after TMI-2 accident are shortly summarized. The experiments in four integral test facilities, LOBI, SPES, BETHSY, ROSA IV/LSTF and the recorded data during a steam generator tube rupture transient in the DOEL-2 PWR (Belgium) were the basis of the five small break LOCA related ISP exercises, which deal with the phenomenon typical of small break LOCAs in Western design PWRs. Some lessons learned from these small break LOCA ISPs are identified in relation to code deficiencies and capabilities, progress in the code capabilities, possibility of scaling, and various additional aspects. ISPs are providing unique material and benefits for some safety-related issues.

Copyright (c) 2008 N. Aksan. This is an open access article distributed under the Creative Commons Attribution License, which permits unrestricted use, distribution, and reproduction in any medium, provided the original work is properly cited.

\section{INTRODUCTION}

Large transient thermal-hydraulic system codes are widely used to perform safety and licensing analyses of nuclear power plants and also used in the design of advanced reactors. Evaluation of the capabilities and the performance of these codes can be accomplished by comparing the code predictions with measured experimental data obtained on different test facilities. In this respect, parallel to other national and international programmes, OECD Nuclear Energy Agency (OECD/NEA) Committee on the Safety of Nuclear Installations (CSNI) has promoted, over the last thirty years some fourty eight international standard problems (ISPs) $[1,2]$. The first international standard problem (ISP) was organized in 1975 on the famous "Edwards blowdown pipe" experiment. These ISPs were performed in different fields as in-vessel thermal-hydraulic behaviour, fuel behaviour under accident conditions, fission product release and transport, core/concrete interactions, hydrogen distribution and mixing, and containment thermal-hydraulics. Roughly, $60 \%$ of these ISPs concerned the thermal-hydraulic behaviour.

The main goal of ISP exercises is to increase confidence in the validity and the use of the different tools that are used in assessing the safety of nuclear installations. These tools may vary to some extent in different countries and are extremely complex. Therefore, the ISPs were considered as an effective way to get a common understanding and judgment about the code/user capabilities on an international basis. Indeed, in an ISP the predictions of different computer codes with respect to a given physical problem may be compared with the results of an experiment or/and among each other. 
While the developmental assessment still belongs to the organisation developing the codes, ISP exercises can be considered as a complementary activity, assessing the codes through the analysis of experts different from the code developers and covering much wider ranges, specifically in terms of thermal-hydraulics scenarios and value of parameters.

The objectives of the ISP may be summarized as

(i) to contribute to better understanding of postulated events,

(ii) to compare and evaluate the capability of codes (mainly best estimate codes),

(iii) to suggest improvements to the code developers,

(iv) to improve the ability of code users,

(v) to address the so called scaling effect.

Standard problems are performed as "open" or "blind" (double blind) problems. In an "open" problem, all participants know the results of the experiment in detail before performing their calculations. In a "blind" exercise, the results are locked until the code users submit the calculation results for comparisons. A so called "double blind" exercise consists of a "blind" one for which no other experimental data related to the test facility has been published or made available to the ISP participants before submission of results. For blind exercises the participants are keenly encouraged to run post test calculations when the experimental results are released. Those post test calculations are sensitivity studies, where various options and/or models are tested in order to see how they affect the results, also to better understand the reasons for eventual discrepancies resulting from comparing "blind" results and experimental data.

As mentioned in [3], both integral and separate effect experiments may be considered for ISP exercise. Also bestestimate codes are preferably used. The reader will also find in the same reference a complete description of the organisation of an ISP exercise.

A global review and synthesis on the contribution that small break LOCA ISPs have made to address nuclear reactor safety issues was initiated by the principal working group no. 2 (PWG2) in September 1993. Further to this request of the PWG2, an action has been put, during the thirteenth meeting of the Task Group on Thermal-Hydraulic System Behaviour (TG-THSB), to carry out this review and synthesis work on previous small break LOCA ISPs. As a result of this synthesis work, a short overview report was written on this subject [4] by a group of experts in the TG-THSB. In order to limit the effort, five ISPs were selected for this evaluation, but not strictly based on small break LOCA scenarios; ISPs in which similar phenomenon to small break LOCA was observed are also considered

(i) ISP 18: LOBI Mod2 1\% small break LOCA [5];

(ii) ISP 20: Doel 2 steam generator tube rupture event [6];

(iii) ISP 22: SPES-simulating loss of feedwater transient in Italian PWR $[7,8]$;

(iv) ISP 26: ROSA-IV LSTF 5\% cold leg small break LOCA experiment [9];

(v) ISP 27: BETHSY 0.5\% small break LOCA with loss of high-pressure injection [10].
The ISPs 18, 22, and 27 were "blind" exercises, while the ISPs 20 and 26 were "open" ones. The ISP 18 is the "oldest" ISP retained in this review and synthesis work, since such an ISP may be considered as a milestone in the transition process between the first generation codes (i.e., RELAP4) and the new generation of advanced computer codes (e.g., TRAC, RELAP5, ATHLET, CATHARE). It is to be noted that there were small break LOCA ISP exercises previous to ISP-18, for example, LOFT and semiscale small break LOCA tests, but they were not considered in this review process due to advancement of the codes relative to the application of the first generation codes in these ISPs. Moreover, at that time some of these new codes were in their development phase. In addition, one may consider that, since 1985, the objectives of ISP were slightly changed due to the reason that all codes passed their developmental phase.

While the ISP 22 initiating event is not a small break, it has been considered in this evaluation since specific phenomena observed during the experiment are similar to those observed during small break accident. Moreover, it might give the opportunity to fill the gap between BETHSY and LOBI test facilities for scaling purposes.

ISP 20 has been retained in this evaluation as far as scaling effect has to be addressed. Indeed, the ISP 20 is the unique exercise based on a transient occurring in a full-scale twoloop PWR nuclear plant.

Other internationally conducted research programmes in this same area have been completed in the time period here considered, including ISPs, for example, ISP 25 and ISP 33. Examples are the OECD-LOFT project or LOBI experiments analyzed by a CEC devoted task group. However, resources limitations and willingness to keep some homogeneity for the discussed transients (i.e., ISP 25 is based on a separate effects test, ISP 33 addressed the behaviour of WWER plants; LOFT is a nuclear facility scaled down with criteria different from those of LOBI, SPES, BETHSY, and LSTF; in addition most of the LOFT, LOBI, and LSTF data were not openly available to the whole OECD community) supported the conclusion to restrict the investigation range, though recognizing the fundamental contributions given by the above mentioned programmes in this same area.

The outcome from each considered ISP and in particular the evaluation of the comparisons between measured and predicted system behaviours are described in detail in the "final comparison reports," from [5] to [10], and therefore will not be repeated here. Identically, this synthesis work will not deal with the "user effects" that has been separately addressed and analyzed in detail in [11].

In this paper, some of the aspects addressed in [4] will be summarized in order to provide an overview on the lessons learned from the small break LOCA ISPs. Section 2 will give an overview on the development of small break LOCA issue. Main phenomena and relevance of small break LOCA to reactor safety in a PWR are shortly described in Section 3. A short overview of ISPs and expected technical findings are dealt within Sections 4 and 5. After a presentation of the involved facilities and plant and a description of the different selected tests (Section 6); Section 7 deals with relevant ISP statistics. Section 8 presents the "lessons learned" from the 
selected ISP activities with some conclusions and recommendations. This also constitutes the main objective of the presented activity.

\section{ORIGIN OF SMALL BREAK LOCA ISSUE (SYSTEM THERMAL-HYDRAULICS BEFORE AND AFTER TMI-2)}

In early 1970s, former US Atomic Energy Commission convened a public hearing to explore the safety question in relation to the effectiveness of systems to mitigate the consequences of a loss of coolant accident in a nuclear reactor, in case it happens. Ultimately, after extensive public hearings, in 1974, the interim regulations were modified to provide a set of specific requirements for computer codes for ECCS analyses in and a new section, 10 CFR 50.46 [12, Appendix K], requiring ECCS meet established standards. This included a definition that LOCAs are hypothetical accidents that would result from the loss of reactor coolant, at a rate in excess of the capability of the reactor coolant makeup system, from breaks in pipes in the reactor coolant pressure boundary up to and including break equivalent in size to the double-ended rupture of the largest pipe in the reactor coolant system. The safety criteria prescribed in 10 CFR 50.46 are applicable to both large and small break LOCAs. That is to say the limits on peak cladding temperature, cladding oxidation, and hydrogen generation must not be exceeded in a design basis accident. Calculations of ECCS performance using the conservative prescriptions of [12, Appendix $\mathrm{K}$ ] resulted in the large break LOCA generally being the most limiting accident. At the time, there was a major safety research programme to support code development for large break LOCA and also some limited work on small break LOCA.

The March 1979 accident at the Three Mile Island Unit 2 (TMI-2) reactor led to an extensive reorientation of light water reactor safety research programmes and also regulatory changes. The TMI-2 accident was a small break LOCA, an event given significantly less attention because of the major emphasize on the large break LOCA at the time. Consequent to TMI-2, small break LOCA and plant operational transients received major attention. The experimental simulation of the natural circulation phenomena in the primary loops, including those in the two-phase stratified and counter-current flow regimes, is of primary importance to the thermal-hydraulic response of a nuclear power plant during such transients. Since these phenomena are significantly dependent on facility scale and geometry, large-scale tests for a primary system geometry representative of operational nuclear power plants are required. Either operational facilities were modified to carry out small break LOCA experiments or there were new facilities designed and constructed (see Section 4). It is to be noted that unlike the large break LOCA, the sequence of events following a small break LOCA can evolve in a variety of ways. Operator actions, reactor design, ECCS set points, break size, and location will have a bearing how the small break LOCA scenario unfolds. Therefore, in order to predict the integral system behaviour during a small break LOCA, a best-estimate code must have sufficient modelling capabilities to take these factors into ac- count. These codes are also needed to be assessed against integral system tests. After having been successfully assessed against data from a large number of scaled test facilities, bestestimate codes become the ultimate repository of all previous thermal-hydraulic safety research. ISP activities are a part of this process (see Section 4).

\section{SMALL BREAK LOCA IN A PWR WITH RELEVANCE TO NUCLEAR REACTOR SAFETY AND MAIN PHENOMENA}

The major characteristic difference between a small break and a large break LOCA is in the rates of coolant discharge and pressure variations with time. In general, small break LOCAs are characterized by an extended period (this can be tens of minutes to several hours at the lower end of the break spectrum) after the occurrence of the break, during which the primary system remains at a relatively high pressure and the core remains covered. As soon as the pumps are tripped, either automatically or manually, gravity-controlled phase separation occurs and gravitational forces dominate the flow and distribution of coolant inside the primary system. The subsequent sequence of events, whether or not the core uncovers and is recovered or reflooded, depends not only on the location, shape, and size of the break, but also on the overall behaviour of the primary and secondary systems. This behaviour is strongly influenced by both automatic and operator initiated mitigation measures. In general, the reactor system response to a small break is slower compared to events after a large break. This allows more time, and different possibilities, for operator interventions. Another principal difference is the domination of gravity effects in small breaks versus inertial effects in the large breaks.

It is to be noted that there is no unique path of development of events following a small break LOCA in PWRs. The scenarios may change drastically by many factors such as the reactor design (e.g., U-tube or once-through steam generators, such as TMI-2), the break size, the core bypass size (allowing some fraction of the inlet cold leg flow directly into the core upper structure without passing through the core), and most importantly, by different operator interactions. As an example, the primary circulation pumps may be shut down early in a small break LOCA transient or they may be allowed to run and circulate the coolant through the core for a long time. These alternative actions can make a large difference in the nature of discharge flow, early heat removal from the core, and the liquid inventory in the system after one hour or so in the transient. Another important possibility of different interactions is through the steam generators. The secondary side of steam generators can be isolated (no feed water flow) or they can be used for a controlled heat removal. It is also possible to cool the reactor through the so-called "feed and bleed" process (on the primary side). Either of these actions will have a major effect on the course of the transient. It is not the intent in this section to provide a catalogue of all possible scenarios following small break LOCA accidents. But it is important to note that an adequate set of modelling capabilities for any of the plausible scenarios will be equally adequate for all 
other relevant scenarios. This is because the phenomena and processes are the same but their interactions and timing of various developments change in different operations. Therefore, in order to predict the integral system behaviour during a small break LOCA, a best-estimate code must have sufficient modelling capabilities to take these factors into account.

During a PWR small break LOCA, there is the potential for three distinct core heat ups. The first heat up is caused by loop seal formation and the manometric core liquid level depression. Naturally occurring events including loop seal clearing and break uncovery mitigate this heat up. The second heat up occurs following the core quench caused by loop seal clearing and is caused by a simple core boiloff. During this period the primary pressure is decreasing to the accumulator set point and the steam produced by the core boiloff leaves the system via the break. Any heat ups that occur during this period are mitigated by the reflood from the accumulator water. The third possible heat up can occur following depletion of the accumulator tanks and before LPIS injection begins. One drawback to the reflood process accompanying the accumulator injection is a decrease in the ongoing depressurisation process such that another possible heat up occurs before the LPIS primary pressure set points are reached and long-term cooling is provided. Various factors affect the magnitudes of the three potential core heat ups. Some examples are break size, break direction and location, availability of HPIS, and the degree of upper head to downcomer bypass flow. Although the magnitudes of the core heat ups may vary, ECCS performance must be such that the criteria, for example, 10 CFR 50.46 [12] is not exceeded.

The interested readers can obtain further details on small break LOCA in [13].

\section{A SHORT OVERVIEW OF ISPS AND TECHNICAL DOMAINS COVERED BY THEM}

A compilation of all ISPs performed between 1975 and 1997 can be found with a brief description of each ISP in [1] and an extended list of ISPs (from 1975 to 2007) is also provided in Table 1.

The very first ISPs from 1975 to roughly 1980 focused on LOCA thermal-hydraulics as it was one of the main concerns of that time. We find there ISPs based on separate effects tests (Edwards blowdown pipe, CISE blowdown test, Battelle blowdown test, tube reflooding test ERSEC) and ISPs based on the two only available system experiments for PWRs at that time, that is, SEMISCALE and LOFT.

After Three Mile Island (TMI-2) accident, ISPs started to move from the large breaks to the small breaks. They included ISPs on LOFT L3 small break LOCA series tests for PWRs, ROSA III, and FIX II tests for BWRs. Some large break tests were still selected: PKL reflooding test, as reflooding was considered as a remaining issue; LOFT L2-5, as it was a significant "concluding" nuclear test for large breaks.

During this period (beginning 80s), two ISPs were initiated in a new domain for ISPs at that time which was the domain of thermo-mechanical fuel behaviour during LOCA.
These were ISPs on REBEKA test (nonnuclear) and on PHEBUS LOCA test (nuclear).

In parallel to the ISPs dealing with the primary circuit, ISPs (in a first step called CASPs) were organized in the beginning of the 80s on containment experiments either system experiments (BATTELLE Model Containment) or very small scale experiment (AAEC-Australia). These ISPs covered large break situations. They were followed in the mid 80 s by ISPs on HDR containment tests (large break in PWR) and Marviken test (BWR).

During the second half of the 80s and during the beginning of the 90s, the ISPs related to thermal-hydraulics were characterized by a full and coherent series based on the experiments which were decided and built after TMI in order to well study small break and transient situations including operator actions. They included ISPs on LOBI-mod2, SPES, ROSA IV, BETHSY facilities for PWRs (lessons learned from these ISPs are provided in [4], summary of which is included in this paper), and PIPER-ONE facility for BWRs. Besides this series, one ISP investigating the effect of noncondensable gases on reflood was performed (ACHILLES), and the first and only one ISP based on real plant was organized in 1988 on the DOEL 2 steam generator tube rupture event.

End of the 80s, the interest of ISPs moved clearly to the severe accident area. ISPs on core degradation were held based on CORA (nonnuclear) and PHEBUS SFD (nuclear). Core concrete interaction was investigated with two ISPs (SURC4 and BETA2). Containment questions and especially hydrogen problems were the subject of two ISPs based on HDR and one ISP based on NUPEC test. In addition, an ISP was also organized on FALCON facility to investigate fission product behaviour with simulants.

One of the extensions of domain covered by ISPs is constituted by the move towards VVER related problems with PACTEL ISP (thermal-hydraulics) and CORA VVER ISP (Core degradation).

In continuation of ISPs on thermal-hydraulics and severe accident, shut down states are investigated with an ISP on BETHSY and steam explosions with an ISP on FARO. STORM and RTF experiments provided data for aerosol behaviour in primary circuit and iodine behaviour in containment under severe accident conditions. UMCP facility was used to assess boron dilution models.

Recent ISPs are PANDA test with six different phases related to passive safety systems for advanced light water reactors; QUENCH-06 and PHEBUS FP-1 tests for severe core degradation; and TOSQAN, MISTRA, and ThAI facilities for containment thermal-hydraulics.

This overview shows the extraordinary large range of technical domains, which have been covered by ISPs. These domains reflect of course the successive changes in the area of concern for nuclear reactor safety research. This demonstrates also that the concept of ISP initiated in the thermalhydraulic area and extended to several other technical areas, is certainly very productive and useful. We will, in the next sections, analyse in general and also for a specific subject of small break LOCA what are the outcomes and the benefits produced by this activity and how it may explain its success. 
TABLE 1: List of CSNI international standard problems (ISPs) [2].

\begin{tabular}{|c|c|c|}
\hline No. & Completion date & Title \\
\hline 1 & 1975 & Standard problem 1-Edwards pipe blowdown test \\
\hline 2 & 1975 & Analysis of semiscale blowdown test 11, LB LOCA \\
\hline 3 & 1977 & $\begin{array}{l}\text { CSNI standard problem 3; comparison of LOCA } \\
\text { analysis codes, CISE, blowdown }\end{array}$ \\
\hline 4 & 1978 & $\begin{array}{l}\text { United states standard problem } 6 \text { and } \\
\text { international standard problem } 4 \text { : comparison of } \\
\text { the standard problem calculations with measured } \\
\text { experimental data for semiscale test S- } 02-6, \text { SB } \\
\text { LOCA }\end{array}$ \\
\hline 5 & 1979 & $\begin{array}{l}\text { United states standard problem } 7 \text { and } \\
\text { international standard problem 5: final } \\
\text { comparison report on LOFT test L1-4, LB LOCA }\end{array}$ \\
\hline 6 & 1978 & $\begin{array}{l}\text { ISP-6: calculations comparison } \\
\text { report-determination of water level and phase } \\
\text { separation effects during the initial blowdown } \\
\text { phase }\end{array}$ \\
\hline 7 & 1979 & $\begin{array}{l}\text { comparison report on OECD-CSNI LOCA } \\
\text { standard problem no. } 7 \text { : analysis of a reflooding } \\
\text { experiment, ERSEC }\end{array}$ \\
\hline 8 & 1979 & $\begin{array}{l}\text { Semiscale MOD1 test S-06-03 (LOFT counterpart } \\
\text { test), LB LOCA }\end{array}$ \\
\hline
\end{tabular}

LOFT test L3-1 preliminary comparison report, SB LOCA

comparison report on OECD-CSNI LOCA standard problem no. 10: "refill and reflood experiment in a simulated PWR primary system (PKL)

LOFT L3-5 and L3-6 comparison reports, SB LOCA

ROSA-III 5\% small break test, Run 912, BWR-SB LOCA

international standard problem 13 (LOFT

experiment L2-5) preliminary comparison report, LB LOCA

behaviour of a fuel bundle simulator during a specified heatup and flooding period (REBEKA experiment) (results of posttest analyses)

LOCA experiment at FIX-II facility, BWR rupture of a steam line within the hdr containment leading to an early two-phase flow: results of posttest analyses: final comparison report

Marviken BWR standard problem

LOBI-MOD2 small break LOCA experiment A2-81

behaviour of a fuel rod bundle during a large break LOCA transient with a two-peaks temperature history (PHEBUS Experiment): final comparison report

Doel 2 steam generator tube rupture event: final report

PIPER-ONE experiment PO-SB-7: simulation of small and intermediate break LOCA for BWRs

SPES-loss of feedwater transient in Italian PWR. final comparison report (1990) and evaluation of posttest analyses (1992). 
Table 1: Continued.

\begin{tabular}{|c|c|c|}
\hline No. & Completion date & Title \\
\hline 23 & 1989 & $\begin{array}{l}\text { Rupture of a large diameter pipe in the HDR } \\
\text { containment }\end{array}$ \\
\hline 24 & 1989 & SURC-4-core-concrete interaction test \\
\hline 25 & 1991 & $\begin{array}{l}\text { ACHILLES-N2 injection from accumulators and } \\
\text { faster (best estimate) reflood rates }\end{array}$ \\
\hline 26 & 1992 & $\begin{array}{l}\text { ROSA-IV LSTF-cold-leg small-break LOCA } \\
\text { experiment }\end{array}$ \\
\hline 27 & 1992 & $\begin{array}{l}\text { BETHSY-small break LOCA with Loss of HP } \\
\text { injection }\end{array}$ \\
\hline 28 & 1992 & $\begin{array}{l}\text { PHEBUS SFD B9+-experiment on the } \\
\text { degradation of a PWR type core }\end{array}$ \\
\hline 29 & 1993 & $\begin{array}{l}\text { HDR experiment E11.2-hydrogen distribution } \\
\text { inside the HDR containment under severe } \\
\text { accident conditions: final comparison report }\end{array}$ \\
\hline 30 & 1992 & $\begin{array}{l}\text { BETA II core-concrete interaction experiment } \\
\text { (Test V5.1): comparison report }\end{array}$ \\
\hline 31 & 1993 & CORA-13 experiment on severe fuel damage \\
\hline 32 & - & FLHT-6 experiment, cancelled \\
\hline 33 & 1994 & $\begin{array}{l}\text { PACTEL-VVER- } 440 \text { natural circulation stepwise } \\
\text { coolant inventory reduction }\end{array}$ \\
\hline 34 & 1994 & $\begin{array}{l}\text { falcon experiments FAL-ISP-1 and FAL-ISP-2, } \\
\text { fission product transport }\end{array}$ \\
\hline 35 & 1994 & $\begin{array}{l}\text { NUPEC hydrogen mixing and distribution test } \\
\text { M-7-1: final comparison report }\end{array}$ \\
\hline 36 & 1996 & $\begin{array}{l}\text { CORA-VVER severe fuel damage experiment (test } \\
\text { W2) }\end{array}$ \\
\hline 37 & 1996 & $\begin{array}{l}\text { VANAM M3-a multi compartment aerosol } \\
\text { depletion test with hygroscopic aerosol } \\
\text { material-comparison report }\end{array}$ \\
\hline 38 & 1997 & $\begin{array}{l}\text { loss of the residual heat removal system during } \\
\text { mid-loop operation (BETHSY) }\end{array}$ \\
\hline 39 & 1997 & fuel coolant interaction and quenching (FARO) \\
\hline 40 & 1999 & $\begin{array}{l}\text { STORM test SR11-aerosol deposition and } \\
\text { resuspension in the primary circuit }\end{array}$ \\
\hline 41 & 1999 & $\begin{array}{l}\text { RTF experiment on iodine behaviour in } \\
\text { containment under severe accident conditions }\end{array}$ \\
\hline 42 & 2003 & $\begin{array}{l}\text { PANDA tests (six different phases) related to } \\
\text { passive safety systems for advanced light water } \\
\text { reactors }\end{array}$ \\
\hline 43 & 2001 & UMCP boron dilution test \\
\hline 44 & 2002 & $\begin{array}{l}\text { Four open and one blind KAEVER aerosol } \\
\text { depletion tests with three differently soluble } \\
\text { materials and uniform thermal-hydraulic } \\
\text { conditions with slight volume condensation }\end{array}$ \\
\hline 45 & 2003 & $\begin{array}{l}\text { QUENCH-06, fuel rod bundle behaviour up to } \\
\text { and during reflood/quench (severe core damage) }\end{array}$ \\
\hline 46 & 2004 & $\begin{array}{l}\text { PHEBUS in reactor experiment (FP-1) on the } \\
\text { degradation, fission product release, circuit and } \\
\text { containment behaviour following overheating of } \\
\text { an irradiated fuel rod bundle }\end{array}$ \\
\hline 47 & 2005 & $\begin{array}{l}\text { Based on experiments performed in the } \\
\text { TOSQAN, MISTRA and ThAI facilities for } \\
\text { containment thermal-hydraulics (e.g., gas } \\
\text { distribution, natural convection, heat and mass } \\
\text { distribution...) }\end{array}$ \\
\hline
\end{tabular}


TABle 1: Continued.

\begin{tabular}{|c|c|c|}
\hline No. & Completion date & Title \\
\hline 48 & 2005 & $\begin{array}{l}\text { Containment capacity (integrity and ageing of } \\
\text { components and structures). } 1: 4 \text { scale model of a } \\
\text { prestressed concrete containment vessel (PCCV) } \\
\text { of a nuclear power plant (SANDIA II mock-up) }\end{array}$ \\
\hline \multicolumn{3}{|c|}{ containment analysis standard problems (CASPs) } \\
\hline CASP-1 & 1980 & $\begin{array}{l}\text { Comparison report on OECD-CSNI containment } \\
\text { standard problem no. 1: "steamline rupture } \\
\text { within a chain of compartments" (Battelle } \\
\text { Institute test D15) }\end{array}$ \\
\hline CASP-2 & 1982 & $\begin{array}{l}\text { Comparison report on OECD-CSNI containment } \\
\text { standard problem no. 2: "water line rupture in a } \\
\text { branched compartment chain" (Battelle Institute } \\
\text { test D16) }\end{array}$ \\
\hline CASP-3 & 1983 & $\begin{array}{l}\text { Final comparison report for containment } \\
\text { standard problem exercise } 3 \text { (australian lucas } \\
\text { heights blowdown/containment rig, small-scale } \\
\text { two-compartments basic containment } \\
\text { experiment) }\end{array}$ \\
\hline
\end{tabular}

\section{THE EXPECTED TECHNICAL FINDINGS FROM ISP ACTIVITY}

The basic material of the technical findings from ISP activity is made of the several predictions obtained with several codes by several code users of a given physical experiment. From these material different cross-comparisons can be made which we will now review.

(i) The first class of comparisons is the comparisons between code predictions and experimental results. Such comparisons are evidently contributing to the code assessment. However, some particularities to this contribution should be emphasized.

(a) This assessment belongs of course to the "independent" assessment. Considering the generally very large number and very large variety of participants to ISPs, the "independent" character is certainly one of the most accentuated that we can afford. For those who are thinking that the independence of assessment is a very important feature, the results of ISPs are unique.

(b) The number of code calculations in the comparison between code predictions and experimental results is certainly the largest that we can imagine on a single test. Almost no individual can do such work at least because of financial limitations. Besides this number of calculations, there are numerous differences in the physical models used in the different codes. The comparisons with experimental results are then very instructive on the effect of these models differences on the capabilities to predict the experiment. Often all codes available in OECD countries (and sometimes in the world) are represented during the ISP execution. A complete international view is then obtained on the status of the predictive capabilities of the phenomena studied in the ISP. (c) It is clear that the large amount of work produced by the participants and by the organizing country requires that no mistake should be done in the process. As a consequence, the experimental test must be first very carefully selected. Therefore, it is very often one of the best and one of the most significant tests of the experimental programme to which it belongs. The organisation of the ISP requires also that all necessary information be transmitted to the participants in a very comprehensive way. Consequently, the organizing country must do a very high control of test results and of documentation. This last requirement led particularly the OECD/NEA working groups to define standards for test documentation. These standards are summarized in the CSNI report no. 17 [3] and have shown to be quite general and useful, in particular, as they have been used in several other areas than ISP. As the need arises, certain revisions are introduced into this report. Finally, the efforts made on the test selection, on the test control and on the test documentation provide most often a technical quality of very high level to the ISPs activities.

(d) The high-level grade of documentation obtained by following the prescribed standards and the strict selection of the tests based on their physical and safety significance make the ISPs tests very good candidates for inclusion in validation matrices. ISPs tests may often be considered as international reference tests. Their already wide distribution and their consequent availability is also a favouring factor for such choices.

(ii) The second class of comparisons is constituted by the comparisons between different codes. It is the common experience of analysts that understanding and analysing the code responses is a very difficult exercise. Indications are most often required in order to give directions for the analyst in 
TABLE 2: Relevant hardware characteristics of considered PWR simulators and Doel-2 nuclear plant.

\begin{tabular}{|c|c|c|c|c|c|c|}
\hline & Quantity & SPES & LOBI/Mod2 & BETHSY & LSTF/ROSA IV & DOEL-2 \\
\hline \multirow[t]{2}{*}{1} & Reference reactor & W-PWR & KWU-PWR & FRA-PWR & W-PWR & W-PWR \\
\hline & Reference reactor power (MWt) & 2775 & 3900 & 2700 & 3423 & 1187 \\
\hline 2 & Mximum power $(\mathrm{MWt}) / \%$ of nominal power & $9.0 / 138$ & $5.4 / 100$ & $3.0 / 10$ & $10.0 / 14$ & $1187.0 / 100$ \\
\hline 3 & Reported $\mathrm{K}_{\mathrm{v}}$ & $1 / 427$ & $1 / 712$ & $1 / 100$ & $1 / 48$ & $1 / 1$ \\
\hline 4 & No. of rods & 97 & 64 & 428 & 1064 & 21659 \\
\hline 5 & Operating pressure of primary loop $(\mathrm{MPa})$ & 15. & 15.8 & 15.51 & 15.5 & 15.5 \\
\hline 6 & Operating pressure of secondary loop $(\mathrm{MPa})$ & 6.1 & 6.54 & 6.91 & $7.3 / 7.4$ & 5.88 \\
\hline 7 & Primary loop volume $\left(\mathrm{m}^{3}\right)$ & 0.622 & 0.643 & 2.88 & 8.3 & 168.5 \\
\hline 8 & No. of U-tubes for each steam generators & $13 / 13 / 13$ & $8 / 24$ & $34 / 34 / 34$ & $141 / 141$ & $3260 / 3260$ \\
\hline 9 & Internal diameter of U-tubes ( $\mathrm{mm})$ & 15.4 & 19.6 & 19.7 & 19.6 & 19.6 \\
\hline 10 & $\mathrm{~L} / \mathrm{D}$ ratio of Hot leg & 57.2 & $73.1 / 119.1$ & 38 & 17.8 & 10.64 \\
\hline \multirow[t]{3}{*}{11} & Total head ("a" in Figure 1) m & & & & & \\
\hline & $\max$ & 16.08 & 16.72 & 18.34 & 18.4 & 14.7 \\
\hline & $\min$ & 15.91 & 16.47 & 16.87 & 16.9 & 13.2 \\
\hline 12 & Linear rod power at $5 \%$ overall power ${ }^{(*)}\left(\mathrm{K}_{\mathrm{v}} / \mathrm{m}\right)$ & $1.27^{(\circ)}$ & 1.08 & 0.86 & 0.91 & 1.12 \\
\hline 13 & Actual $\mathrm{K}_{\mathrm{v}}^{(+)}$ & $1 / 640$ & $1 / 619$ & $1 / 144$ & $1 / 48$ & $1 / 2.5$ \\
\hline
\end{tabular}

${ }^{(*)}$ The $\%$ value is the power related to the reported $\mathrm{K}_{\mathrm{v}}$.

${ }^{(+)}$Related to LSTF.

${ }^{(\circ)}$ To compensate heat losses.

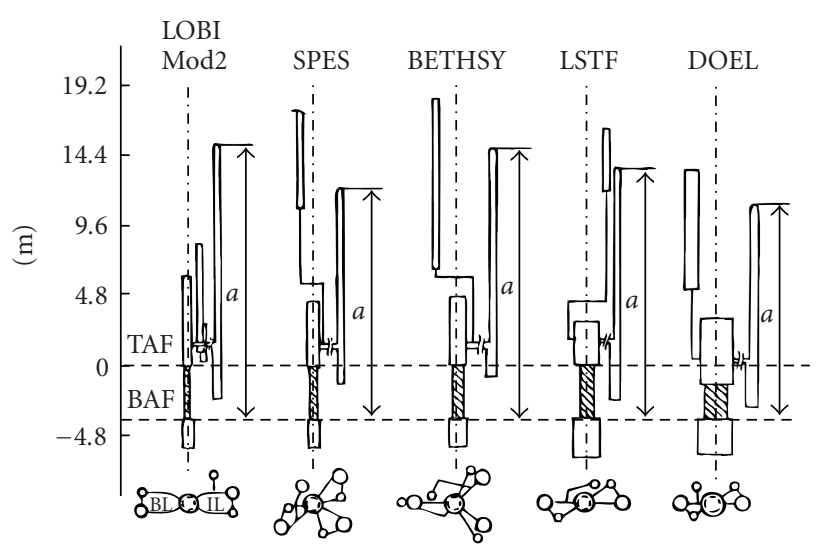

Figure 1: Sketch of the facilities considered for the experimental data base evaluation.

its search of understanding the physical models pertinence. A first group of indications is given by the analysis of the discrepancies between calculations and experimental results, which has been discussed above. A second group relates to the discrepancies between the results of different codes. This last group is often very valuable because the differences of models between the codes can be quite easily identified. Consequently, the analyst can focus immediately on the concerned physical models and evaluate their relative capabilities in reference with the experimental data. By the wide variety of codes used, ISPs give good opportunities for doing extensive analysis of this kind.

(iii) The last category of comparisons, which ISPs allow, is the comparison of the results obtained with the same code by different users. The major differences between the calcu- lations with the same code can be mainly attributed to the users of the code and this effect has been called the "user effect." Indeed this effect is a major finding of ISPs activity. It has been discovered very early by running the very first ISPs on thermal-hydraulics. The development of thermalhydraulic advanced codes was expected to decrease this effect, but the last thermal-hydraulic ISPs have shown that there was still a significant "user effect" with these advanced codes. Detailed studies of this effect have been made on different ISPs and especially on ISP 26 [11]. In addition to the identification of the user effect, ISPs have contributed largely to its understanding. ISPs are really providing data, which are absolutely unique on this crucial subject. Even though some suggested ways to reduce the user effect have been proposed, it remains that we are quite far from controlling it. This user effect has also appeared as a generic question and not only in the thermal-hydraulics area where it has been discovered. In particular the several ISPs, which have been recently performed in the severe accidents area, have shown the importance of such an effect.

In the coming sections, specific analysis and further discussions will be provided on selected small break LOCA and transient ISPs.

\section{OUTLINE OF INVOLVED FACILITIES AND TESTS FOR SB-LOCA ISPS}

\subsection{Facilities and plant hardware}

In this section, information is given concerning some hardware features that are relevant for the considered ISP tests. Figure 1 shows the sketch of LOBI, SPES, BETHSY, and LSTF facilities and of the Doel plant. 
The relative elevations of important system components like core, steam generators U-tubes, loop seals can be seen; the number of loops constituting the system is reported too. The most important design parameters of the considered facilities and of the plant are given in Table 2. All the considered facilities can operate at the reference plant nominal pressure for both primary and secondary loops. The height scaling ratio is equal to one in all cases, so the gravity heads are properly simulated. The maximum allowed power is equal to the reference reactor value multiplied by volume scaling ratio only in the cases of LOBI and SPES. In other cases, a decay power value is allowed, ranging around $10 \%$ of the nominal value. This scaling limitation prevents, among the other things, the possibility to have simultaneously rightly scaled temperatures and flowrates in nominal conditions. In these facilities, the choice is generally made to preserve hot leg fluid temperature during steady state operation, before any transient; alternatively, it is possible to preserve the cold leg fluid temperature and nominal flowrate (hot leg temperature not preserved); as a consequence of the former choice, secondary side fluid temperature and pressures must be higher than the reference plant nominal values (a real plant at hot standby conditions, $10 \%$ of nominal power, exhibits the same behaviour, roughly 70 bar at secondary side); still, primary pumps have not the maximum allowable flowrate and head properly scaled, although in the case of BETHSY, primary pumps have full flowrate capacity and preserve the head in single phase flow conditions. The different criteria utilized for the pressurizer result from Figure 1, as well for defining the minimum elevation of the loop seal. In the facilities (SPES, BETHSY, and LSTF), the L/ $\sqrt{ } \mathrm{D}$ scaling is adopted for the design of hot and cold legs piping also preserving the volume scaling [14].

Nevertheless, the position of the hot leg axis with respect to the top of the active fuel may be not the same as in the reference nuclear power plant; in BETHSY, this position is preserved with respect to the reference reactor, as well the bottom line of the cold leg elevation to the bottom of active fuel, this leads to different elevations for hot and cold leg axes. For all the multiloop facilities, each primary (and secondary) circuit is equal to the other; thus nearly symmetrical thermal-hydraulic conditions occur in the various loops. An exception is represented by LOBI, where one loop (intact) simulates three loops of the reference reactor and the other simulates a single (broken) loop. Hardware parameters like pump geometrical configuration, presence, and characteristics of bypass flow paths (mostly in the vessel) can play an important role in the considered test scenarios.

\subsection{Outline of the experimental scenarios}

The experiments A2-81, SP-FW-02, SB-CL-18, 9.1b, and the SGTR transient, respectively from LOBI, SPES, LSTF, and BETHSY facilities and Doel plant (Figure 1 and Table 2), were submitted by the facility owner organisations to the CSNI and were discussed and approved at working group and principal working group levels. The list of host organisations (i.e., proposing the exercise, writing the final reports, and chairing the workshops) for each ISP, is given in Table 3.
TABLE 3: List of host organisations for small break LOCA related ISPs.

\begin{tabular}{ll}
\hline ISP & Host organisation \\
\hline 18 & JRC (Ispra) \\
20 & TRACTEBEL (Brussels) \\
22 & ENEA (Rome) \\
26 & JAERI (Tokai Mura) \\
27 & CEA/CENG (Grenoble) \\
\hline
\end{tabular}

The procedures outlined in [3] for assignments of ISPs have been generally followed.

The main characteristics of the mentioned tests are reported in Table 4. The main phenomena occurring during SB-LOCAs are listed in Table 5 [15], making use of a phenomena matrix developed in state-of-the-art report (SOAR) on emergency core cooling thermal-hydraulics [15]. In the same table, a qualitative evaluation of the capabilities of facilities is provided, according to three judgment levels. For completeness and in order to give an example of the possible use of this table, in the last two columns, an overall evaluation of the Relap5/Mod2 and CATHARE codes in addition to their performances is reported, considering each of the phenomena listed and the pre- and posttest calculations [15].

The significant trends of variables with reference to the selected tests are shown in Figures 2 through 7, while details of the experiments are given below.

ISP 18: The test in LOBI simulated a $1 \%$ cold leg break with HPIS intervention (Figure 2). From a phenomenological point of view, the whole transient can be divided into three main phases:

(i) the forced circulation period,

(ii) the two-phase natural circulation period,

(iii) the reflux condensation period.

During the first phase, after the opening of the break device, the primary system pressure decreases down to $13.2 \mathrm{MPa}$ within 32 seconds, triggering both SG isolation and core power decay. Simultaneously, secondary system cooling is activated causing an upper limit to the increase in secondary pressure. At 45 seconds pumps coast down begins and at 74 seconds HPIS starts to inject water into the primary system. At 121 seconds pump coast down completion ends the forced circulation phase, and two-phase natural circulation is established in the loops. As voiding proceeds, natural circulation stops and heat exchange with the secondary system is accomplished by reflux condensation occurring in the steam generator U-tubes.

An important feature of the test is the liquid mass distribution inside the primary loop which is affected by the bypass flow paths in the vessel and by heat transfer across steam generators mainly during natural circulation and reflux condensation periods. Since HPIS is sufficient to avoid core uncovery, no dry out is measured during the test.

ISP 20: The considered transient in Doel plant is the steam generator tube rupture (SGTR) accident (with a longitudinal crack of $7 \mathrm{~cm}$ long located in the ascending leg of 
TABLE 4: Main characteristics of the considered transient.

\begin{tabular}{|c|c|c|c|c|c|c|c|}
\hline $\begin{array}{l}\text { ISP } \\
\text { ident. }\end{array}$ & Facility/plant & Test & Type & $\begin{array}{l}\text { Secondary side } \\
\text { significant } \\
\text { conditions }\end{array}$ & $\begin{array}{l}\text { Emergency systems } \\
\text { in primary side }{ }^{(*)}\end{array}$ & $\begin{array}{l}\text { Recovery } \\
\text { procedure }\end{array}$ & $\begin{array}{c}\text { End of test } \\
\text { (s) }\end{array}$ \\
\hline ISP 18 & LOBI & A2-81 & $\begin{array}{l}\text { SBLOCA } A_{b}= \\
1 \% A_{\max } \text { in cold leg }\end{array}$ & Imposed $100 \mathrm{~K} / \mathrm{hr}$ & HPIS in cold leg & $\begin{array}{l}\text { Secondary system } \\
\text { feed and bleed }\end{array}$ & 4500 \\
\hline ISP 20 & DOEL & SGTR 1979 & $\begin{array}{l}\text { SGTR } A_{b}=0.5^{(+)} \% \\
\text { of } A_{\max }\end{array}$ & $\begin{array}{l}\text { EFW and steam } \\
\text { Relief valves active }\end{array}$ & $\begin{array}{l}\text { HPIS in cold leg: } \\
\text { pressurizer sprays } \\
\text { and heaters }\end{array}$ & - & 3000 \\
\hline ISP 22 & SPES & SP-FW-02 & $\begin{array}{l}\text { LOFW-loss of feed } \\
\text { water }\end{array}$ & $\begin{array}{l}\text { Boildown of } \\
\text { secondary side and } \\
\text { EFW active in one } \\
\text { loop }\end{array}$ & $\begin{array}{l}\text { Pressurizer PORV } \\
\text { and heaters }\end{array}$ & EFW in one loop & 8000 \\
\hline ISP 26 & LSTF & SB-CL-18 & $\begin{array}{l}\text { SBLOCA } A_{b}=5 \% \\
\text { of } A_{\max }\end{array}$ & $\begin{array}{l}\text { Steam relief valves } \\
\text { active }\end{array}$ & $\begin{array}{l}\text { Accumulators and } \\
\text { LPIS in cold leg }\end{array}$ & RHR actuation & 1000 \\
\hline ISP 27 & BETHSY & 9.1.b & $\begin{array}{l}\text { SBLOCA } A_{b}= \\
0.4 \% \text { of } A_{\max }\end{array}$ & $\begin{array}{l}\text { EFW } \\
\text { and pressure } \\
\text { control active }\end{array}$ & $\begin{array}{l}\text { Accumulators and } \\
\text { LPIS in cold leg }\end{array}$ & $\begin{array}{l}\text { Depressurizarion } \\
\text { of secondary side }\end{array}$ & 8000 \\
\hline
\end{tabular}

${ }^{(*)}$ scram is assumed in all cases following a low pressure signal.

${ }^{(+)}$rough evaluation

the U-bend of one of the U-tubes) occurred in Doel plant in 1979 and constituted the first (and, so far, the unique) standard problem related to a plant system (Figure 3). At the moment when the event occurred, the reactor was subcritical with all control rods down and the pressurizer heaters on. In the secondary side, the steam lines were both isolated by the MSIV and no condenser vacuum was available. The main feed water pumps were not operational and water level in both SGs was manually controlled by means of a letdown system. The auxiliary feed water pumps were not running. The plant conditions remained well below the safety margins during the whole transient.

The condensation induced by the pressurizer spray and in the secondary side of steam generators at the liquid-steam interface is the relevant phenomena to be predicted by codes. However, quite large uncertainties characterize the trends of the main quantities as well as the time of actuation of the main systems, typically reflecting the features and capabilities of plant instrumentation and recording systems.

ISP 22: The test in the SPES facility consists of a loss of feed water with delayed actuation of emergency feed water in one of the three loops of the facility. The transient evolves through 5 phases (Figures 4 and 5) from the following.

(i) The accident beginning to scram: due to the loss of feed water, the downcomer level drops quickly in each steam generator. As the low level set point is achieved, the scram occurs, causing the core power to shutoff and the main steam isolation valves to close.

(ii) Scram to pressurizer PORV opening: after scram a quick depressurization occurs in primary side as a consequence of temperature decrease. The steam generators U-tubes then dry out, the primary temperature rises continuously, causing primary system pressurization up to the pressurizer PORV opening.

(iii) Pressurizer PORV opening to pumps trip: while the primary temperature is rising continuously and is approaching the saturation value, the pumps are switched off when the fluid subcooling at the inlet reaches the set point value.

(iv) Pumps trip to emergency feed water activation: due to the progressive voiding of the primary side, a core heat up occurs and the emergency feed water activation signal in one of the steam generators is generated by the high rod surface temperature set point.

(v) Emergency feed water activation to the end of the transient: emergency feed water activation causes a quick repressurization in the affected steam generator and reestablishes heat transfer between the primary and the secondary sides, with a consequent big decrease of primary temperature and pressure. The secondary level in the affected steam generator increases steadily until the initial value is restored.

The following main features of the test can be pointed out.

(i) The pressure control of the primary system by the pressurizer PORV cycling and the consequent mass depletion cause rod surface temperature excursion roughly two hours after the transient beginning.

(ii) The actuation of emergency feed water in one loop leads to primary system depressurization, pressurizer draining, core quench, and brings the facility to safe shut down conditions, allowing the possibility of accumulators actuation.

ISP 26: The experiment in the LSTF test facility is originated by a $5 \%$ break in the cold leg of the loop without pressurizer, the HPIS is not available (Figure 6). Following the break opening the primary pressure went down and scram occurred at 9 seconds. The core was temporarily uncovered, at first time, between about 120 and 155 seconds after break opening. The reason for this was a core level depression amplified by a manometric effect caused by condensation at the top of $\mathrm{U}$-tubes and consequent liquid holdup in 
TABLE 5: Suitability of tests facilities, judgment of the experiments, and (example of) evaluation of RELAP5/Mod2 and CATHARE code capabilities as from [13].

Facilities $\quad$ Experiments

Phenomena SPES LOBI/Mod2 BETHSY LSTF ISP 18 ISP 20 ISP 22 ISP 26 ISP $27 \begin{gathered}\text { RELAP5/Mod2 Code CATHARE V } 1.3 \\ \text { Performance }^{(\circ)} \quad \text { Code Performance }^{\circ}\end{gathered}$

Natural circulation

in one-phase flow,

primary side

Natural circulation

in two-phase flow,

primary side

Reflux condenser

mode and CCFL

Asymmetric loop

behaviour

Leak flow

Phase separation

without mixture

level formation

Mixture level and

entrainment in

steam generator

secondary side

Mixture level and

entrainment in the

core

Stratification in

horizontal pipes

Emergency core

cooling mixing and $\mathrm{o}$

condensation

Loop seal clearance +

Pool formation in

upper

plenum/CCFL

Core wide void and flow distribution

Heat transfer in covered core

Heat transfer in

partially uncovered o

core

Heat transfer in steam generator primary side

Heat transfer in steam generator secondary side

Pressurizer

thermal-hydraulics

Surge line

hydraulics (CCFL,

chocking)

One and two-phase pump behaviour

Structural heat and heat losses

$++$

$+$

o $\quad$ o

$+\quad$ o

o

$+$

O

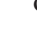

$+\quad$ o


TABLE 5: Continued.

\begin{tabular}{|c|c|c|c|c|c|c|c|c|c|c|c|}
\hline \multirow[b]{2}{*}{ Phenomena } & \multirow[b]{2}{*}{ SPES } & \multicolumn{3}{|c|}{ Facilities } & \multicolumn{5}{|c|}{ Experiments } & \multirow[b]{2}{*}{$\begin{array}{l}\text { RELAP5/Mod2 Code } \\
\text { Performance }^{(\circ)}\end{array}$} & \multirow[b]{2}{*}{$\begin{array}{l}\text { CATHARE V } 1.3 \\
\text { Code Performance }\end{array}$} \\
\hline & & LOBI/Mod2 & BETHSY & LSTF & ISP 18 & ISP 20 & ISP 22 & ISP 26 & ISP 27 & & \\
\hline $\begin{array}{l}\text { Noncondensable } \\
\text { gas effect on leak } \\
\text { flow }\end{array}$ & - & + & o & o & - & - & - & - & - & $x$ & $x$ \\
\hline $\begin{array}{l}\text { Phase separation in } \\
\text { T-junctions }\end{array}$ & o & o & + & + & o & - & - & + & + & - & + \\
\hline $\begin{array}{l}\text { Thermal-hydraulic } \\
\text { nuclear feedback }\end{array}$ & - & - & - & - & - & - & - & - & - & $x$ & $\times$ \\
\hline $\begin{array}{l}\text { Boron mixing and } \\
\text { transport }\end{array}$ & - & - & - & - & - & & - & - & - & $x$ & $\times$ \\
\hline $\begin{array}{l}\text { Separator } \\
\text { behaviour }\end{array}$ & - & - & - & - & - & - & - & - & - & $x$ & $x$ \\
\hline
\end{tabular}

${ }^{(\circ)}$ The best performance of the code is considered due to number of submissions.

Note: the following symbols are used in this table; for test facility versus phenomenon: + suitable for code assessment, o limited suitability, - not suitable, for phenomenon versus experiments: + experimentally well defined, o occurring but not well characterised, - not occurring or not measured, for phenomenon versus code calculation: + well predicted, o qualitatively predicted, - not predicted, $\times$ not applicable.

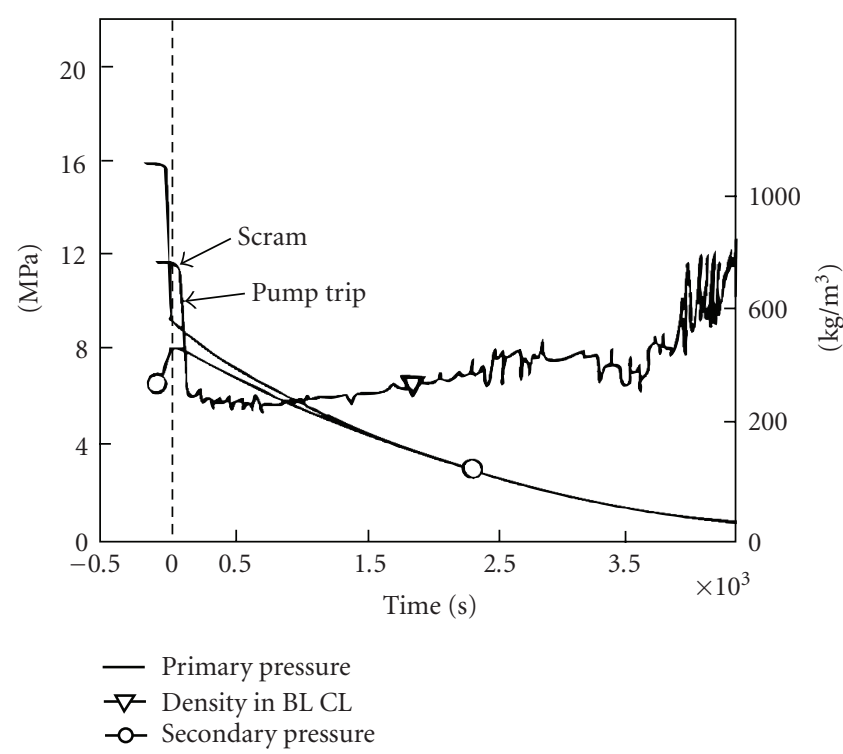

Figure 2: ISP-18 (LOBI): experimental trends of primary and secondary side pressures and broken loop cold leg density.

the ascending and descending legs of U-tubes. At about 140 seconds, loop seal clearing occurred and caused a temporary core temperature recovery. After loop seal clearing, the break flow changed from low quality to high quality two-phase flow and the depressurization of primary loop was accelerated. By about 180 seconds after the break, the primary loop pressure decreased below steam generator secondary side pressure. Thereafter, the steam generator no longer served as heat sink and the energy removal from the primary system occurred through the discharge of coolant from the break. It is noted that loop seal clearing occurred before the reversal in primary and secondary pressures. The core was uncovered again after about 420 seconds due to vessel inventory

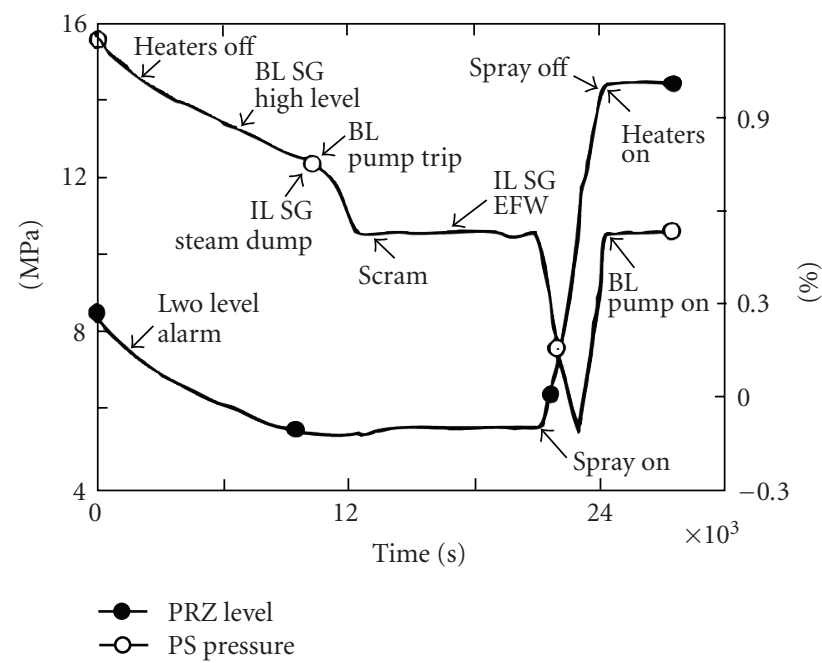

FIgURE 3: ISP-20 (Doel-2): registered data trends of primary side pressure and pressurizer level.

boiloff; the heater rods in the upper part of the core showed superheating up to about $80 \mathrm{~K}$. The core was covered with two-phase mixture again after about 540 seconds by the accumulator water injection. The peak cladding temperature in the test was approximately $740 \mathrm{~K}$, observed during the temporary core uncovery just before the loop seal clearing.

The occurrence of two dry out and quench conditions constitutes the main peculiarity of this transient. The mass distribution in the loop and the heat transfer with secondary side constitute further challenging phenomena for code assessment.

ISP 27: The test in BETHSY facility is an SBLOCA with the break (roughly $0.5 \%$ ) located in the cold leg of the loop 


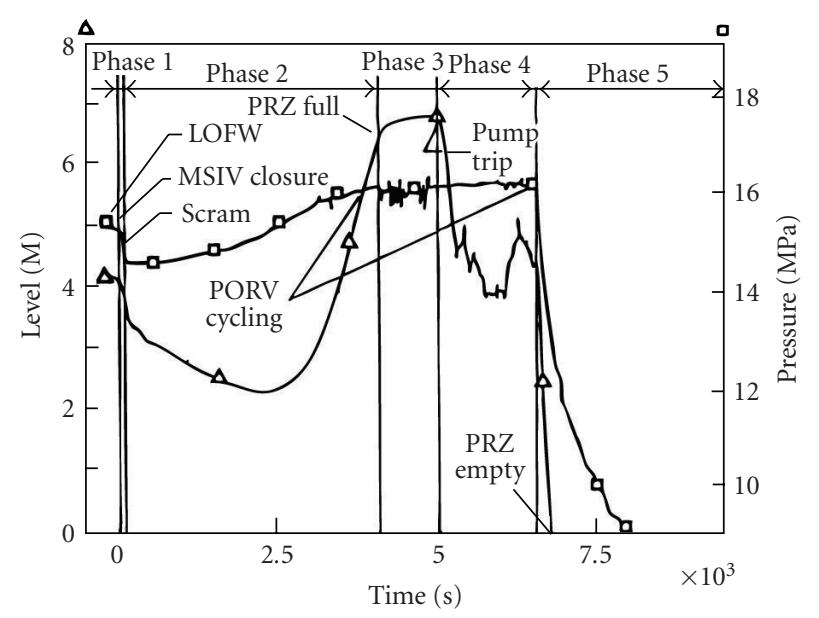

Figure 4: ISP-22 (SPES): experimental trends of pressurizer pressure and level.

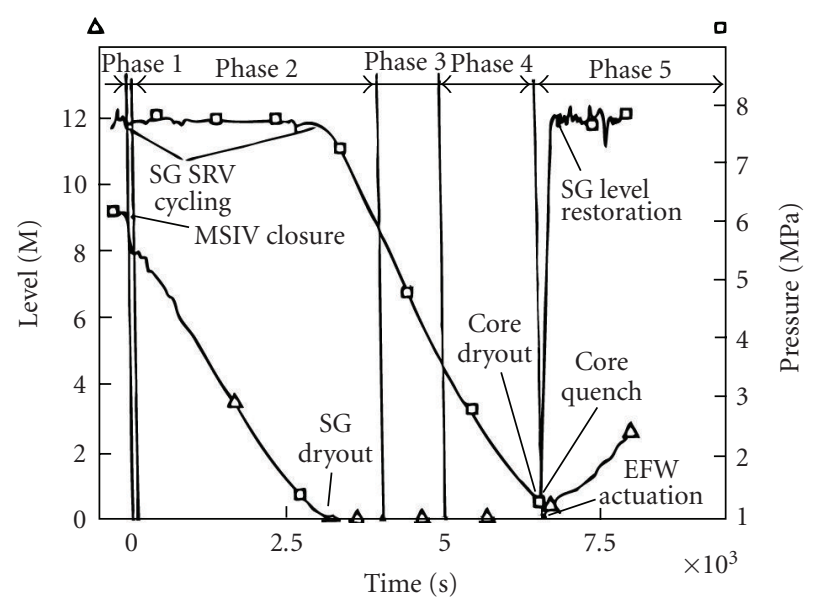

FIGURE 5: ISP-22 (SPES): experimental trends of steam generator pressure and level.

with the pressurizer (Figure 7); HPIS is not available. Three different phases can be recognized during the transient:

(i) subcooled blowdown;

(ii) mass depletion in primary side;

(iii) ultimate procedure.

\section{Subcooled blowdown}

Following the break opening the primary pressure falls down and scram occurs when the pressure reaches $13.1 \mathrm{MPa}$. safety injection signal (SI) occurs at 11.9 MPa. Following SI signal, turbine bypass occurs and main feed water is off. Before SI, secondary side pressure is controlled through the spray condenser and remains constant at $6.91 \mathrm{MPa}$; when turbine bypass occurs the pressure threshold becomes 7.03 MPa. Auxiliary feed water injection starts 30 seconds after SI signal, and pump coast down initiates 300 seconds after the same signal. During this phase, the pressurizer and surge line empty leading to the relatively fast depressurization of the primary

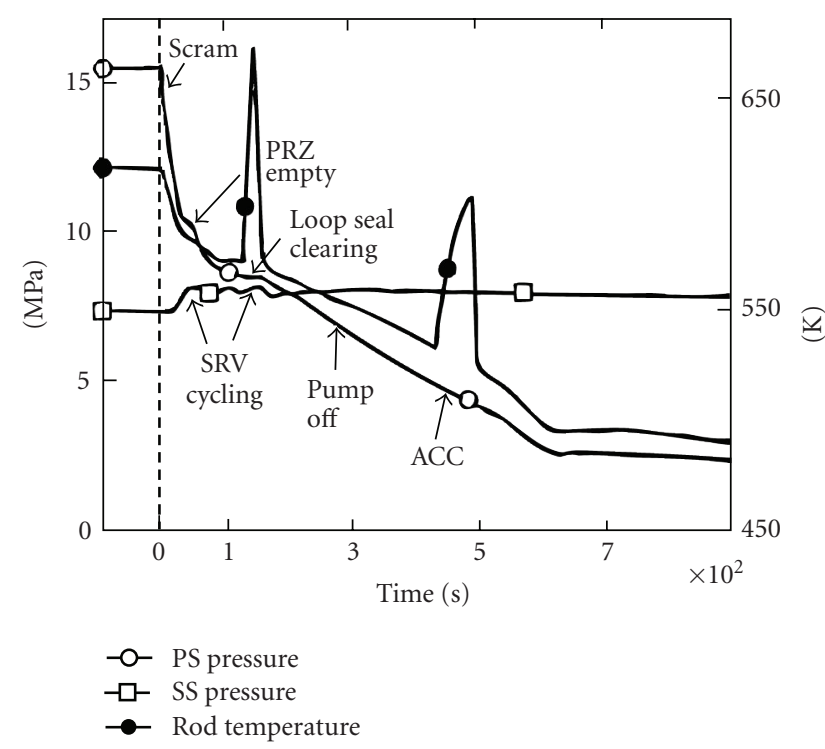

FIgure 6: ISP-26 (ROSA-IV): experimental trends of primary and secondary side pressures and rod surface temperature.

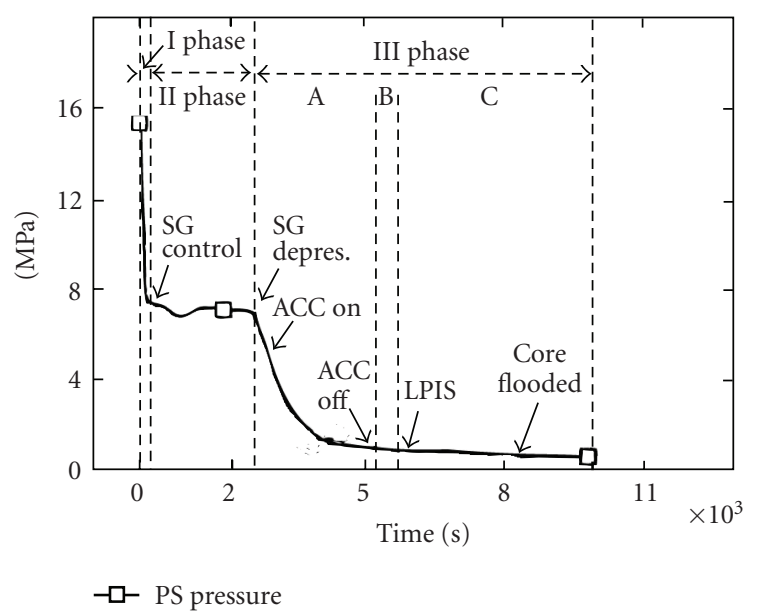

FIGURE 7: ISP 27 (BETHSY): experimental trend of primary side pressure.

side; in the same period owing to the diminution of the heat transfer from primary to secondary side, the mass flowrate in the secondary side starts to decrease.

\section{Mass depletion}

The second phase is characterized by mass depletion and almost constant pressure and temperature in primary loop (saturation values). Oscillations in break flowrate in the first period of phase 2 testify of little voiding of the cold leg of the broken loop. Later on, with pumps at rest, once the upper head to downcomer bypass steam flows to the broken cold leg, mostly steam flows at the break (stratified conditions with liquid level upstream the break lower than the elevation of the exit nozzle axis). Loop seal clearing is recognized to 
appear in only one of the two intact loops and stops with the occurrence of the first core uncovery. Secondary side conditions (mostly levels) remain constants in this period. At the end of this phase, a second core uncovery occurs, which causes the trip for the predefined ultimate procedure when the core maximum clad temperature reaches $723 \mathrm{~K}$.

\section{The ultimate procedure}

This phase of the test consists in fully opening the dump valves in secondary side due to accumulators and LPIS actuation; three different parts can be distinguished during the last phase of the transient ( $\mathrm{A}, \mathrm{B}$, and $\mathrm{C}$, resp.). In the part A, starting with the ultimate procedure initiation and ending with accumulators isolation, intense condensation in the U-tubes induces liquid fall back to the core, which is cooled from the top, then accumulator injection allows the clad temperature to turn around and the core to be rewetted. Part $\mathrm{B}$ is related to the period from the accumulators' isolation up to LPIS actuation. A continuous mass depletion of primary side without ECC injection characterizes this phase. No dry out situation occurs in this period during which the primary pressure decreases down to achieving the set point for LPIS actuation. Very early during part C, LPIS flowrate becomes larger than break flowrate leading to recover the primary coolant system. In this period filling up the primary loop occurs causing, among other things, direct contact condensation between the cold liquid injected by LPIS and the steam present in the primary loop.

\section{THE RESULTS OF SOME STATISTICAL ANALYSIS FOR SMALL BREAK LOCA ISPS}

In the framework of the ISP activity evaluation, interesting information may come from the statistical analysis considering the number of participants to the ISP, including countries and organisations, as well as the adopted thermal-hydraulic system codes. The main goals of the effort are to get an overview of the interest towards the ISP activity from the international scientific community, and to derive information about the engagement by different organisations in the use of large thermal-hydraulic system codes.

A wide database is available for making statistical evaluations; this is included in the ISP reports approved and issued by CSNI and in the individual ISP participants written contributions normally distributed (among participants) at the ISP workshops. A comprehensive analysis would require establishing homogeneous indices for interpreting the data, for example,

(i) computers have strongly evolved lowering the needed calculation time in the period 1985-1995 (in some cases, the calculation time increases just because transients take longer times);

(ii) codes having sophisticated capabilities of noding a specific zone of nuclear power plant (i.e., volume component in CATHARE) may need less overall number of node for having the same detail of plant description; (iii) once an acceptable convergence is reached from a numeric point of view, the increase in number of time steps might not lead to any benefit; calculation time may be reduced by the progress in physical modelling reducing the interaction number and meshing size.

However, a number of quantities could be used to characterize the results of an extended statistical analysis, for example, [16]. Following a discussion among the participating working group members, it was found that most of the data (e.g., numbers of used meshes or nodes) averaged on the number of participants could be misinterpreted or even misleading considering the present situation. This is originated by the reason outlined above, specifically, including the different levels of qualification of the scientists directly involved in the calculation and even the different purposes for organisations in participating in an ISP. As an example, it was found that the consideration of the number of input deck nodes for the different participants should not give a reasonable index of the "quality" of user nodalization itself.

The lack, in the ISP documents of an exhaustive description of calculation resources, prevented the possibility to use the time needed for the calculation of ISP exercises, as a parameter eventually identifying a "code speed" index.

Keeping in mind the above, the following quantities were selected for the present analysis:

(i) kind and number of participants to the ISP,

(ii) thermal-hydraulic codes used for the ISP calculation.

In relation to the first item, it seemed interesting to correlate the participants with the different ISPs and with the adopted codes used, considering the total number of participations to the ISPs for each participant.

The second item gives an idea of the differences in the use of each code. It must be emphasized that the results of the analysis might not be indicative of the actual number of users for each code. More detailed information in this context should be gathered by specific collaborative programmes like Club des Utilisateurs du CATHARE (CUC), Code Assessment and Maintenance Program (CAMP) or specific "institutionalized” series of conferences like Relap5 International Conference.

Specific parameters to characterize the two items identified above, which were retained suitable for evaluating the overall impact of ISP activity in the scientific community are

(1) number of participants to the specific ISP,

(2) participants per ISP,

(3) number of countries per ISP,

(4) participants per code per ISP,

(5) codes used per ISP.

ISP phases (e.g., pre- and posttest) are considered in Tables 6, 7,8 and the information related to items (1) to (5) are given in these tables. As already mentioned, further information on statistical evaluation, considering a large number of parameters, can be found in $[4,16]$. It is to be noted that there are six types of organisations who participated in the small break LOCA ISP exercises. These are covering a wide range of organisations: research centres, universities, licensing 
TABLE 6: Participants per code per ISP.

\begin{tabular}{lcccccccc}
\hline & $\begin{array}{l}\text { ISP 18 } \\
\text { pretest }\end{array}$ & $\begin{array}{c}\text { ISP 18 } \\
\text { posttest }\end{array}$ & $\begin{array}{c}\text { ISP 20 } \\
\text { posttest }\end{array}$ & $\begin{array}{c}\text { ISP 22 } \\
\text { pretest }\end{array}$ & $\begin{array}{c}\text { ISP 22 } \\
\text { posttest }\end{array}$ & $\begin{array}{c}\text { ISP 26 } \\
\text { posttest }\end{array}$ & $\begin{array}{c}\text { ISP 27 } \\
\text { pretest }\end{array}$ & $\begin{array}{c}\text { ISP 27 } \\
\text { posttest }\end{array}$ \\
\hline RELAP4/Mod6 & 2 & 1 & - & 3 & 2 & - & 1 & 1 \\
RELAP5/Modl & 10 & 1 & 1 & 1 & - & - & - & - \\
RELAP5/Mod2 & 4 & 4 & 5 & 4 & 1 & 7 & 10 & 11 \\
RELAP5/Mod2.5 & - & - & - & - & - & 2 & 1 & 1 \\
RELAP5/Mod3 & - & - & - & - & - & - & 7 & 6 \\
CATHARE 1 & 1 & 1 & - & - & - & - & - & - \\
CATHARE 2 & - & - & 1 & 1 & 2 & 1 & 3 & 6 \\
TRAC/PF1 & 3 & 1 & - & 4 & - & 1 & 1 & - \\
DRUFAN-M2 & 3 & - & - & - & - & - & - & - \\
ATHLET 1.0 & - & - & - & - & - & 1 & 1 & - \\
SMABRE & - & - & 1 & 1 & - & 3 & - & 1 \\
NOTRUMP & 1 & - & - & 1 & - & 2 & - & - \\
FRACAS & 1 & - & - & - & - & - & 1 & - \\
Dinamyka & - & - & - & - & - & - & - & - \\
Tech-m4 & - & - & - & - & - & - & - & - \\
Moot & - & - & - & 1 & - & - & - & - \\
ATHENA & 1 & - & - & - & - & - & 1 & - \\
SATAN-M & - & - & - & - & - & - & - \\
\hline
\end{tabular}

authorities, industry, utility, and others (e.g., engineering companies).

Detailed statistical data and analysis are included in [4]; in this paper, a few conclusions drawn from the analysis of the statistical data are given as follows.

(i) A large number of codes have been used in the different ISPs. It is possible to see a predominant use of RELAP family of codes specifically from most of universities and research centres.

(ii) A number of participants still use first generation (e.g., RELAP4) or proprietary codes (NOTRUMP).

(iii) The number of participants increased after ISP 20 essentially due to the fact that since the time of ISP 22, the ISP activity was open for the non-OECD countries. The positive effect was to allow Eastern countries to get information about Western countries safety methodologies. A "negative" impact of this was the increment of the scientists participating to the ISP for the first time, making more difficult to get objective conclusions from the discussions about the ISP itself.

(iv) The use of well established or "frozen" versions of codes allows the verification of the degree of assessment of the concerned code version against a full transient.

(v) Fourty six organisations took part in the small break LOCA ISP activities; very few organisations took part to more than five of the considered ISP cases.

(vi) Of the above organisations, almost $82 \%$ belong to the research/university side (specifically, 54\% research institutes and $28 \%$ universities).

\section{SOME LESSONS LEARNED FROM THE SMALL BREAK LOCA ISP ACTIVITY}

The contents of this section are based on the answers received to a questionnaire [4] that was sent to fourteen members of TG-THSB who were involved in the analysis of most of the small break LOCA ISPs, from the conclusions included in each of the ISP final report (CSNI reports, [5] to [10]), and from the discussions of a working group, which took place during the meeting in Pisa University in 1995.

As mentioned in Section 7, eighteen different codes were used by the participants for these ISPs. It is not the purpose here to produce a detailed analysis of calculational performances, code by code, and ISP by ISP; but in a more synthetic approach, to derive the main outcomes from the five ISPs, specifically taking into account the following four items identified in the questionnaire:

(i) code deficiencies and capabilities,

(ii) progress in the code capabilities,

(iii) possibility of scaling,

(iv) other comments.

It should be mentioned that from ISP 18 to ISP 27, more and more physical phenomena were involved in the transients which were dealt within the ISP exercises, such as coreuncovery and heatup, pressurizer discharge, secondary side voiding and filling, low pressure two phase flows as well as interacting operator actions. The involvement of various phenomena during an ISP exercise must be considered as challenging for the codes, and as well as code users. Furthermore, increasing overall complexity and longer time durations of the transients to be calculated, can be noted during 
TAble 7: Countries, Participants, and Codes used per ISP.

\begin{tabular}{|c|c|c|c|c|}
\hline ISP & Type & No. of participants & No. of countries & No. of codes \\
\hline ISP 18 & Pretest & 27 & 11 & 8 \\
\hline ISP 18 & Posttest & 6 & 6 & 5 \\
\hline ISP 20 & Posttest & 7 & 5 & 4 \\
\hline ISP 22 & Pretest & 17 & 14 & 8 \\
\hline ISP 22 & Posttest & 4 & 4 & 3 \\
\hline ISP 26 & Posttest & 17 & 14 & 9 \\
\hline ISP 27 & Pretest & 23 & 17 & 9 \\
\hline ISP 27 & Posttest & 17 & 14 & 7 \\
\hline
\end{tabular}

(*) Note: the numbers reported in the number of participants column do not coincide with the sum of the numbers in Table 6 because either a single participant might have submitted more than one calculation officially recognized, or a group of participants took part together in the ISP submitting a single calculation.

TABLE 8: Calculations per code groups per ISP.

\begin{tabular}{|c|c|c|c|c|c|c|c|c|}
\hline Codes & $\begin{array}{c}\text { ISP I8 } \\
\text { pre }\end{array}$ & $\begin{array}{c}\text { ISP } 18 \\
\text { post }\end{array}$ & $\begin{array}{c}\text { ISP } 20 \\
\text { post }\end{array}$ & $\begin{array}{c}\text { ISP } 22 \\
\text { pre }\end{array}$ & $\begin{array}{c}\text { ISP } 22 \\
\text { post }\end{array}$ & $\begin{array}{c}\text { ISP } 26 \\
\text { post }\end{array}$ & $\begin{array}{c}\text { ISP } 27 \\
\text { pre }\end{array}$ & $\begin{array}{r}\text { ISP } 27 \\
\text { post }\end{array}$ \\
\hline RELAP family of codes & 16 & 6 & 6 & 8 & 3 & 9 & 19 & 19 \\
\hline CATHARE family of codes & 1 & 1 & 1 & 1 & 2 & 1 & 3 & 6 \\
\hline TRAC family of codes & 3 & 1 & - & 4 & - & 1 & 1 & - \\
\hline Others & 6 & - & 1 & 3 & 一 & 9 & 3 & 2 \\
\hline Total & 26 & 8 & 8 & 16 & 5 & 20 & 27 & 27 \\
\hline
\end{tabular}

the process of going from the earlier to the latest considered small break LOCA ISPs.

\subsection{Code deficiencies and capabilities}

The code user is clearly the best judge of the performance of his own calculations. The invested resources, the depth of the quality assurance used when setting up the nodalization, and the possibility to interact with the experimentalists play a major role in the quality of the results, this can only be known to the user. So, in order to get a general, but not in depth evaluation of submitted results, two steps were considered as follows:

(a) list of relevant thermal-hydraulic phenomena in each test, making reference to the list in Table 5, also looking at the facilities suitability;

(b) identification of phenomena which were not well predicted by the majority of submitted calculations.

The quality of experimental data also had a role in selecting code deficiencies. A list of generic code deficiencies, which were identified, is provided in Table 9. As code deficiency, it was meant a situation where either the phenomenon is not predicted to occur in the calculation, or the phenomenon was predicted but at a given time the quantity $\left|\mathrm{Yc}-\mathrm{Y}_{\mathrm{E}}\right| /\left|\mathrm{Y}_{\mathrm{E}}\right|$ was larger than 0.20 (see also [9]). In this case, $\mathrm{Y}$ is a relevant thermal-hydraulic quantity representing the assigned phenomenon and the deviation of calculated from experimental quantity.

It can be seen from Table 9 that thirteen main code deficiencies have been found, some of those being common to different ISPs. A comprehensive and systematic qualitative or quantitative code calculation accuracy evaluation is well beyond the scope of the present paper. In this respect, some example results are provided in $[8,9,17]$ in relation to ISPs22, 26 , and 27, respectively. Slightly different criteria are adopted for achieving either a qualitative judgment (e.g., good, average, and poor) or a quantitative evaluation (e.g., quantification of the accuracy through the fast fourier transform(FFT-) based method). For this type of evaluations, the interested researcher could refer directly to the mentioned documents. Additional notes on selected items are provided below.

Let us first deal with the break flowrate problem (item 1) in Table 9 appearing in all ISPs, but not in ISP 20 and 22; many participants have experienced wrong predictions of this parameter among the ISPs, leading to deviation (sometimes large) from the actual transient. Although a very accurate prediction of this quantity is not requested for safety studies, where a stated range of break flowrate may be and is generally used, the capability of codes to reasonably predict two-phase critical flowrates versus leak geometry and upstream conditions becomes significant when the efficiency of operator actions (use of discharge devices, e.g.) has to be investigated. For the considered ISPs, various levels of agreement on the break flowrate predictions were observed, and these results were often correlated with the resources invested in this part of the work and the user's experience in this field. It appears however that some break models are still having difficulty to calculate for the whole range of break upstream conditions. In this area, an example of complex interaction between code nodal inadequacies, user assumptions, 
TABLE 9: General code deficiencies for the considered ISPs.

\begin{tabular}{|c|c|c|}
\hline ISP no. & Identification no. of Deficiency & Code deficiencies \\
\hline \multirow{4}{*}{18} & (1) & Break flow \\
\hline & $(2)$ & Stratification in cold and hot leg \\
\hline & (3) & Mass distribution in primary side \\
\hline & $(4)$ & Mixing in the downcomer \\
\hline \multirow{2}{*}{20} & (5) & Steam condensation \\
\hline & $(6)$ & Level simulation in secondary side \\
\hline \multirow{6}{*}{22} & (6) & Unability to predict mass inventory in secondary side \\
\hline & $(7)$ & Heat transfer between EFW and hot SG walls \\
\hline & $(8)$ & Pressurizer behaviour including PORV leak \\
\hline & (9) & Coolant mass distribution in primary circuit \\
\hline & $(1)$ & Break flow \\
\hline & $(2)$ & Stratification in cold and hot leg \\
\hline \multirow{3}{*}{26} & $(10)$ & CCFL in SG plena \\
\hline & $(3-11)$ & Core level depression \\
\hline & $(12)$ & Core uncovery and heat-up \\
\hline \multirow{6}{*}{27} & (1) & Break flow \\
\hline & (2) & Stratification in cold and hot leg \\
\hline & (3) & Mass distribution in primary side \\
\hline & (4) & Mixing in the downcomer \\
\hline & $(12)$ & Core uncovery and heat-up \\
\hline & $(13)$ & Low pressure period \\
\hline
\end{tabular}

interpretation of data provided by experimentalists is given in [18] by using the RELAP5 code. This sensitivity study about break discharge coefficients, performed during the ISP 27 posttest analysis, showed the large influence of this parameter upon the time scale shifting appearing in blind calculations. Even though, these coefficients had been previously adjusted by using the separate effect test experimental data provided by the ISP host organisation. This mentioned study pointed out and also emphasized the need for code assessment procedures to verify the overall agreement on integral test transients.

However, in general, break flow can be largely influenced by the upstream flow conditions, which are strongly related to the mass distribution in the entire system and to the overall system behaviour. Therefore, just "tuning" the break flowrate might introduce a compensation of errors and, as well as, it might result in complete wrong conclusions. This also results in excluding to provide the ISP participants with the measured break flow. For complicated geometries (such as valves), geometry effects on break flow are even more important. The critical flow performance of the valves must be characterized and supplied as input to the code.

Another key parameter in these considered ISPs is the coolant mass distribution in the primary circuit (item 3 in Table 9, relevant to ISPs 18, 22, and 27), which is strongly related to the two-phase structure and flow regimes. Interfacial shear stresses, counter-current flow limitations, transitions between flow regimes are directly related to the coolant mass distribution. The need for a better prediction of this distribution prompted the development of second-generation ("advanced") two-phase thermal-hydraulic codes. These codes proved their ability to qualitatively predict the physical phenomena involved during the different transients, such as stratified flows in horizontal pipes, loop seal clearing, interfacial transport in core, and steam generator U-tubes. Nevertheless, some weaknesses revealed during the first of the considered ISPs and, concerning void distribution in vertical or horizontal components, still appeared unresolved in ISP 27 (see Table 9).

Additional specific comments are connected with the thermal coupling between fluid and structures, both in primary and secondary sides. This is a consequence of both the scaling ratio of the facilities involved, and of the operating procedures applied; this has been a subject of discussion during most of the ISP related workshops. Inaccuracies due to different reasons in accounting for the fluid structure and thermal coupling, that is, lack of suitable noding and inadequate consideration of heat losses, may have a role in various calculation discrepancies. In every case, codes have demonstrated their ability to qualitatively describe these phenomena (fluid-structures heat transfer), provided that a sufficient amount of care and work had been spent to correctly define the geometry and thermal boundary conditions.

In ISPs 26 and 27 discrepancies remain in predicting core heatup, though fluid distribution is predicted adequately. Similarly "hot wall delay" effect in steam generators downcomer is not satisfactorily calculated in ISP 22. These examples raised questions about the relevant heat transfer models in the considered conditions.

At last, some specific aspects specifics for one or two ISPs, such as secondary side level prediction (ISPs 20 and 22), and low pressure refilling of the primary coolant system (ISP 27), 
highlighted model weaknesses in these fields for most of the codes.

From the point of view of the code capabilities, it must be indicated that experienced users are able to get the relevant phenomena even in the case when complex scenarios are involved. Such a qualitative judgment has been supported by quantitative evaluations, that is, quantification of accuracy considering experimental and calculated trends, in the cases of ISP 22 and ISP 27 (see also below).

However, looking generally to a single ISP, a wide range of results is achieved even considering the use of same code versions. This emphasizes the role of the user in setting up the nodalization and also in interpreting the initial and boundary conditions supplied by the experimentalists. In conclusion, in an ISP framework, owing to different reasons (see also below) the user effect may overshadow the reasons for code deficiencies, thus preventing the possibility to identify code capabilities

\subsection{Identification of progress in code capabilities}

Firstly, it must be emphasized that one of the reasons why progress is difficult to measure, is that it is difficult to isolate phenomena in an integral test. Owing to this fact, it is also difficult to judge even making reference to each single code, since there is also no clear feedback between the ISP activity and the code developers, as already mentioned. In fact, ISPs have been proved more useful to provide information on the capabilities of the thermal-hydraulic codes, especially when posttest calculations or parametric studies were conducted, than to identify the deficiencies or failures. In this case, returning to the use of more analytical work or separate effect tests is however necessary to modify or extend the individual physical models; this step has allowed some progress in code capabilities. The direct contact condensation, or stratification and phase separation models in horizontal pipes constitute an example of this.

Progress was also observed in using parallel channel simulation in attempting to better represent $2 \mathrm{D}$ or $3 \mathrm{D}$ behaviours with the codes used, which are basically one dimensional. One of the most important progresses has been obtained in the area of users guidelines. Thanks to the large number of participants, often using the same code versions, with different nodalizations and option choices, the ISP preand posttest calculations, formed a wide "database" for the so called "user effect."

The small break LOCA ISPs provided a useful information basis, not only for experienced code users to increase their capability from one ISP to the other, but also for new code users to improve their know-how by exchanging ideas and meeting more experienced people in the frame of ISPs.

\subsection{Possibility of scaling}

Although the considered five ISPs address the problem of scaling, either because the plant transient is expected to be very similar to that observed in the facilities which are properly scaled, or because of the different scales of the facilities addressing the same thermal-hydraulic phenomenon, or be- cause a plant transient is considered (ISP 20), the commonly reached conclusion is that small break ISPs alone are not sufficient to check code accuracy in this field. The counterpart tests performed making reference to the same scenario in terms of boundary and initial conditions, on different facilities, are much more valuable for this task $[17,19,20]$.

However, it is considered interesting to bring to the attention hereafter the results of a common evaluation, which was made in preparing CSNI report on "lessons learned from OECD/CSNI ISP on small break LOCA" [4].

Two items are identified to judge the possibility of using the small break LOCA ISP exercises in scaling activities.

(A) Realism of involved physical phenomena as far as plant is concerned.

(B) Possibility to assess the code in different scaled facilities in relation to the same scenario (evaluation whether the small break LOCA ISP scenario can be found in different scaled facilities).

The analysis of each small break LOCA ISP related to the above two items gives the following results.

(i) ISP 18, item (A): test scenario expected to be similar in the plant.

(ii) ISP 18, item (B): limited suitability because the test scenario not available in other facilities.

(iii) ISP 20, item (A): this is a plant scenario.

(iv) ISP 20, item (B): the same scenario has been considered in one of the LOBI experiment.

(v) ISP 22, item (A): qualitatively, phenomena expected to be the same as in the plant, but timing is different.

(vi) ISP 22, item (B): test suitable for scaling because the same experiment was repeated in different facilities.

(vii) ISP 26, item (A): plant scenario expected to be the same (local phenomena might be different).

(viii) ISP 26, item (B): test suitable for scaling because the counterpart test activity deals with similar scenario.

(ix) ISP 27, item (A): plant overall scenario expected to be the same.

(x) ISP 27, item (B): difficult to assess the code scaling capabilities, because the similar test scenario is not available from other facilities.

As a result of the above, ISP 22 and ISP 26 related experiments appears to be the most suitable for studying scaling. Even though it is a plant, ISP 20 mostly suffers of limitations due to inadequacy of the database obtained from the plant, both in relation to plant hardware and data recording, as already mentioned.

\subsection{Other comments}

An additional outcome from the small break LOCA ISP activity in the second half of 90s appeared is linked to the area of works about quantitative accuracy evaluation of codes. The results of the calculations for ISP 22 and ISP 27 have been used to check some of these methods and proved very useful for this purpose $[16,21]$.

Another lesson from these small break LOCA ISPs concerns the experience gained by the code users in performing 
calculations on various facilities and transients, improving their understanding of the code capabilities and weaknesses. Opening this activity to Eastern countries (since ISP 22) was thus a unique opportunity specifically for small countries to have access to relevant experimental data, and to improve their know-how in relation to the use of codes and nuclear reactor safety.

A further lesson from small break LOCA ISPs concerns the identification and characterization of user effects [11]. Different code users utilizing the same code version and getting the same available information from experimentalists (ISP host organisation) produce quite different results especially in "blind" standard problems, but as well as in "open" standard problems. ISP 25 (not included in the present study) and ISP 26 (here considered) were used as basis for the influence of the user on the results of calculations (see [11]). Among the various out comings, it was found that, potentially, user effects can be very important and may overshadow code deficiencies or capabilities (same conclusion as in Section 8.1).

\section{CONCLUSIONS}

The ISPs are part of an important ongoing programme promoted by OECD/CSNI during the last thirty years and gave, among the other things, the possibility to disseminate the safety culture and to homogenize the knowledge of scientists from different countries of the world, in a relevant area of the nuclear technology. In addition, the ISP activity gives a real challenge to all participants to analyze an experiment in detail in the frame of an international activity and compare the own calculation results with other results (and the data). Furthermore it is a big challenge to all codes, which are used for comparing with the other codes.

The present work focuses on a limited part of the entire programme, making reference to five ISPs that deal with phenomenon typical of small break LOCAs in PWRs. Four different facilities based on experiments and an actual plant transient are involved. The considered set of standard problems represent an answer in the system thermal-hydraulic area to the concerns raised by the TMI- 2 accident and have been proposed in a period when advanced codes have been made available; definitely, the discussed ISPs and the advanced codes might be considered as complementary elements for ensuring reliability in safety evaluations in the area of long lasting transients (as opposed to short transients like large break LOCA) potentially affected by operator actions.

In the frame of the presented activity, the involved experimental facilities and the reference tests have been characterized adopting the list of twenty two phenomena proposed when setting up the CSNI code validation matrix for integral test facilities. This led to establishing qualitative similarities among the different transient scenarios and demonstrated that the latest small break LOCA ISPs, which were performed in the largest scale facilities, cover much broader ranges of phenomena relevant to nuclear reactor thermal-hydraulics.

Whatever is the kind of ISP, "blind," "open," "double blind," the quality of a calculation, that is, the degree of agreement between code results and experimental data, de- pends upon several factors ranging from capabilities of code physical models, to user experience, to nodalization details and qualification, to the quality of the information supplied by the experimentalists, integration of this information into the input of the codes. So, as already mentioned, finalized conclusions regarding the submitted calculations cannot be drawn without the direct contributions of the code users and the experimentalists; on the other hand, this is the subject of the comparison reports issued by OECD as a summary of each ISP, they are listed here as references.

Considering the above, the conclusions reached are of a quite general nature and involve aspects that are common to the different ISPs, as well as to small break LOCA related ISPs.

It was noted that large numbers of countries (more than 20) and organisations (more than 50) took part at least in one small break LOCA ISP: these essentially include all countries using nuclear power to generate electricity (one exception strictly connected with political reasons can be observed). However, only few organisations participated in all the considered ISPs and many organisations took part in one ISP only. Furthermore, in the recent years the number of code users increased and among these users, there were less experienced ones; this must be considered carefully when deriving conclusions from the ISP activities. Assuming that the advanced codes were available to most of the participants since the time of the ISP 18 (first of the considered ISP), this together with the statistical evaluations done in the frame of Section 7 and [4], lead to the following conclusions.

(a) The objectives in the participation to the ISP changed over the time, being mostly connected with code development at the beginning and mostly focused toward user training in the latest ISP; this might not be true for codes that did not reach an adequate maturity at the beginning of the considered time frame.

(b) Notwithstanding the large effort necessary to organize or even to participate in an ISP, the cumulative experience gained by a single organisation or by a single group of scientists inside one organisation is generally not transferable or at least has not been transferred. This is especially true in a nonnegligible number of cases where the participant organisation or the group of scientists dissolved and did not leave any track of the acquired experience. This concerns code developers, experimentalists, and code users, and may be considered as a problem common to the whole area of system thermal-hydraulics.

(c) The ISPs got more demanding with the time. There was a significant progress in the code capabilities; for example, the ISP 27 (BETHSY) could be calculated only with very large difficulties (or in some cases could not be calculated at all) at the time period when the ISP 18 (LOBI) was performed.

A list of thirteen deficiencies coming from the considered ISPs and common to most of the utilized codes has been identified as in Section 8.1. This is not an exhaustive list, but underlines one positive result of ISP exercises. However, it must be observed that very slow or almost no progress has been done in the identified areas in the past decade. 
An additional aspect that should be brought to the attention is that the ISPs are not part of a general finalized code assessment programme that, historically, has been the objective of cooperations like International Code Assessment Program of USNRC (ICAP), Code Assessment and Maintenance Program of USNRC, follow up to ICAP (CAMP), Club des Utilisateurs du CATHARE (CUC), and so forth or of nationally funded researches. In most of the cases, this prevented a direct improvement of codes based on the results of ISPs (see also below), although code deficiencies detected in the frame of ISPs, owing to the relevance of the ISPs themselves, were always brought to the attention of code developers.

Furthermore, inadequacy or lack of direct feedback from the results of ISPs to code model improvements is in some cases the consequence of the need to fix time frames and deadlines; this may prevent the achievement of "optimized" results with an assigned code version. For some particular codes, too frequent releases of different code versions also put obstacles as far as that feedback is concerned. The use of ISPs as exercise for proving or achieving some user qualification, also contributed to the above conclusion.

Although a detailed evaluation/judgment of each ISP activity is not the purpose of the effort done in the present framework, it seemed worthwhile to add few specific conclusions applicable to single ISPs.

(i) A large mismatch may exist between the huge effort from the host organisation and the participants as a whole on one side, and the final result of the exercise.

(ii) Incomplete or even misleading information supplied by the host organisation in some cases testify of the complexities of the general code assessment problem and could hinder to facilitate the achievement of meaningful conclusions.

(iii) In some cases, participants underestimated the effort necessary to set up suitable nodalization including correct consideration of initial and boundary conditions; this constitutes an additional reason preventing more satisfactory conclusions of the activities.

(iv) Especially, as a consequence of the above, quite vague formulations can be found in the general conclusions of the ISP reports.

(v) A large range of results obtained by participants using the same code version gives interesting information about uncertainty in selection of input parameters and uncertainties of code models as well as experimental data errors (see [11]).

\subsection{Recommendations}

General recommendations coming from the performed activity can be summarized as follows, covering different aspects connected with small break LOCA ISPs.

(i) The participation into ISP activities of non-OECD countries should be continuously encouraged; especially small countries not having the capabilities for wide national research programmes, can get substantial benefits from ISPs.

(ii) Notwithstanding obvious drawbacks (e.g., lack of suitable instrumentation, inaccuracy of data base, etc.) a future ISP based on an actual plant transient, if any, is highlyrecommended. (iii) A better characterization of the experiments of ISPs, also in view of a qualitative evaluation of code performance, could be based on the 67 phenomena identified for the CSNI separate effects tests code validation matrix made available in mid 90 s [22, 23], future ISPs should directly consider this.

(iv) The interaction between ISP host/proposing organisation and CSNI working groups has been quite satisfactory as far as the test selection is concerned, but could be improved especially in relation to the evaluation of the results and for defining the impact of these in the thermal-hydraulic and nuclear safety areas.

(v) The inadequacy of a direct feedback (indirect feedback may exist) between ISPs results and code developers has already been stressed. However, indirect feedback exists, as ISPs revealed the important role played by physical phenomena such as phase separation at the junctions, stratification in horizontal components (ISP 18), or secondary side heat transfer (ISP 27). Then, valuable information for improving the code model must be the result of independent confirmatory analyses performed utilizing data from separate effects tests facilities (SETF), for example, a code inadequacy possibly identified when performing the analysis of one ISP in an integral test facility should be confirmed and characterized by calculations based on SETF experiments. In this sense, SETF-based ISPs are also strongly recommended.

(vi) The list of code deficiencies given in the Section 8.1 could be used as basis for planning future ISPs in separate effects tests facilities together with phenomena relevant in 2D/3D geometrical configurations. Clearly, codes should also be improved as far as possible, when a model inadequacy is found.

(vii) "Blind" types of ISPs should be preferred to "Open" types, especially when a posttest ("Open") phase of the ISP can be planned and reliable data can be supplied to the participants since the beginning. This gives a better opportunity to evaluate the user effect and better represents the overall situation that is faced when performing plant related calculations.

(viii) The experience acquired so far, the database available from different national and international programmes and the cost of an ISP, suggests not to propose additional ISPs in the frame of small break LOCAs; transients evolving at low pressure, scenarios involving complex accident management procedures or of specific interest for the new generation reactors are not part of this recommendation.

(ix) Some of the discussed ISPs have been utilized as sample basis for addressing the problems of user effects and quantification of the accuracy of calculation results. However, some specific efforts should be devoted from future ISP host organisations, possibly in cooperation with CSNI, in the areas of user effects, user qualification, and quantification of the accuracy. It could even be standard part of the ISP activity.

(x) In relation to user effect, in a long-term view, a part of the problem can be solved by improved codes, which remove the need for the user to make ad hoc assumptions in order to compensate for code limitations or complete lack of modelling; an example of this is modelling pressure drop at geometric discontinuities. 
(xi) In connection with the above, when applicable, the problem of evaluating the uncertainty by system thermalhydraulic codes when predicting scenarios relevant to nuclear power plants could be addressed in the frame of activities similar to the ISPs.

Finally, considering the effort expended in the preparation of ISPs, it would be very useful if this information was catalogued and stored so that it could be easily accessed for future posttest analyses.

\section{NOMENCLATURE}

$A_{b}$ : $\quad$ Broken area size of steam generator tubes

$A_{\max }$ : $\quad$ Maximum area size of steam generator tubes

ACC: Accumulators

BAF: $\quad$ Bottom of active fuel

BL: $\quad$ Broken loop

CAMP: Code Assessment and Application Programme of U.S. NRC

CEA: Commissariat pour l'Energie Atomic

CEC: Commission of European Community

CENG: Centre d'Etudes Nucleaires Grenoble (present name: CEA Grenoble)

CL: $\quad$ Cold leg

CSNI: Committee on the Safety of Nuclear Installations

CUC: Cub des Utilisateur du CATHARE

D: Diameter

ECC: Emergency core cooling

EFW: $\quad$ Emergency feed water

ENEA: Ente nazionale energie alternative

HPIS: High-pressure injection system

ICAP: International Code Assessment Program of U.S. NRC (predecessor of CAMP)

IL: Intact loop

ISP: International standard problem

JAERI: Japan Atomic Energy Research Institute

JRC: Joint European Centre

$\mathrm{K}_{\mathrm{v}}$ : Volume scaling factor

L: $\quad$ Length

LOCA: Loss-of-coolant accident

LOFW: Loss of feed water

LPIS: Low-pressure injection system

MSIV: Main steam isolation valve

NEA: Nuclear energy agency

OECD: Organisation for Economical Cooperation and Development

PORV: $\quad$ Power operated relief valve

PRZ: $\quad$ Pressurizer

PS: $\quad$ Primary side

PSI: $\quad$ Paul Scherrer Institut

PWG-2: Principal working group on system behaviour

PWR: Pressurized water reactor

RHR: Residual heat removal

SBLOCA: Small break LOCA

SG: $\quad$ Steam generator

SGTR: Steam generator tube rupture

SI: $\quad$ Safety injection

SRV: $\quad$ Safety relief valve
SS: $\quad$ Secondary side

TAF: $\quad$ Top of active fuel

TG-THSB: Task Group on Thermal-Hydraulic System Behaviour

TMI-2: $\quad$ Three Mile Island Unit 2

\section{ACKNOWLEDGMENTS}

The author is grateful to F. D'Auria and V. Faluomi (University of Pisa, Italy), L. Vanhoenaker (TRACTEBEL, Brussels, Belgium), H. Staedtke (JRC Ispra, Italy), P. Clement (CENG, Grenoble, France), J. Erikson (Studsvik, Nykoping, Sweden), H. Glaeser (GRS Garching, Germany), J. Lillington (AEA Technology, Winfrith, UK), and R. Pochard (IPSN:DPEICEA/FAR, Fontenay-Aux-Roses, France) who are the major contributors to the CSNI report on "Lessons learned from OECD/CSNI ISP on small break LOCA" [4].

\section{REFERENCES}

[1] OECD, "CSNI international standard problems (ISP): brief description (1975-1997)," Tech. Rep. NEA/CSNI/R(97)3, OECD/NEA, Paris, France, July 1997.

[2] M. Reocreux and N. Aksan, "Contribution from twenty-two years of CSNI international standard problems," OECD/NEA report, NEA/CSNI/R(97)29, Paris, France, March 1998.

[3] OECD/NEA, "CSNI standard problem procedures," Tech. Rep. 17, OECD/NEA, Paris, France, November 1989, CSNI Report, OECD/NEA/GD (94)/82, 1994.

[4] "Lessons learned from OECD/CSNI ISP on small break LOCA," OECD/NEA report written by group of experts, NEA/CSNI/R (96) 20, OCDE/GD (97) 10, July 1996.

[5] H. Staedtke, "ISP 18: LOBI-MOD2 small break LOCA experiment final comparison report," CSNI Report no. 133, Paris, France, September 1986.

[6] M. De Feu, M. Firnhaber, R. Pochard, and E. Stubbe, "ISP 20: doel-2 steam generator tube rupture event: final report," CSNI Report no. 154, 1988.

[7] G. De Toma, S. Ederli, E. Negrenti, P. Marsili, and N. Pignatelli, "OECD/CSNI ISP 22: draft comparison report," NEAG 1 TP413 90009, March 1990.

[8] W. Ambrosini, M. Breghi, P. F. DAuria, and G. M. Galassi, "ISP 22: SPES loss of feedwater transient in Italian PWR: final comparison report and evaluation of post test analysis," CSNI Report no. 174- NEA/CSNI/R (92) 7, Paris, France, April 1992.

[9] Y. Kukita, H. Nakamura, T. Watanabe, et al., "ISP 26: ROSAIV LSTF cold leg small break LOCA experiment: comparison report," Tech. Rep. NEA/CSNI/R (91) 13, OECD/NEA, Paris, France, February 1992.

[10] P. Clement, T. Chataing, and R. Deruaz, "ISP 27: BETHSY small break LOCA with loss of HP injection," NEA/CSNI R(92) 20, Paris, France, November 1992.

[11] S. N. Aksan, F. D'Auria, and H. Staedtke, "User effects on the transient system code calculations," NEA/CSNI/R (94) 35, January 1995.

[12] 10 CFR 50.46, "Acceptance criteria for emergency core cooling systems for light water cooled nuclear power reactors," Appendix K to 10 CFR part 50-ECCS Evaluation Models, US Cod of Federal Register, January 1974.

[13] M. J. Lewis, R. Pochard, F. D’Auria, et al., “Thermohydraulics of emergency core cooling in light water reactors-a state of the art report," Tech. Rep. 161, OECD/NEA, Paris, France, October 1989. 
[14] F. D'Auria and H. Karwat, "OECD/CSNI state of the art report on thermalhydraulics of emergency core cooling systemsreview of the operation of experimental facilities," University of Pisa Report, DCMN NT 138(89), Pisa, Italy, OECD-CSNI Report SINDOC (89)101, Paris, France, August 1989.

[15] C. Billa, F. D’Auria, N. Debrecin, and G. M. Galassi, "Application of relap5/Mod2 to PWR international standard problems," in Winter Meeting of the American Nuclear Society (ANS '91), San Francisco, Calif, USA, November 1991.

[16] F. D'Auria, M. Leonardi, and R. Pochard, "Methodology for the evaluation of thermalhydraulic code accuracy," in Proceedings of International Conference on New Trends in Nuclear System Thermalhydraulics, Pisa, Italy, May-June 1994.

[17] R. Bovalini, F. D'Auria, and G. M. Galassi, "Scaling of complex phenomena in system thermalhydraulics," Journal of Nuclear Science and Engineering, vol. 115, no. 2, pp. 89-111, 1993.

[18] F. De Pasquale, M. Sencar, and S. N. Aksan, "Bethsy 2" cold leg break with accident management procedures (ISP 27): blind and post-test analysis calculations using the RELAP5/Mod2.5 code," in Proceedings of the 1st Code Application and Maintenance Program Meeting (CAMP '92), PSI, Villigen, Switzerland, May 1992.

[19] A. Annunziato, C. Addabbo, G. Briday, et al., "Small break counterpart tests in the LSTF, BETHSY, LOBI and SPES test facilities," in Proceedings of the 5th International Topical Meeting on Nuclear Reactor Thermal Hydraulics (NURETH-5), Salt Lake City, Utah, USA, September 1992.

[20] F. D’Auria, G. M. Galassi, and M. Ingegneri, "Evaluation of the data base from the small break LOCA high power and low power tests performed in PWR experimental simulators LOBI and SPES," in Proceedings of the 1st International Symposium on Two-Phase Flow Modelling and Experimentation, Rome, Italy, October 1995.

[21] W. Ambrosini, R. Bovalini, and F. D'Auria, "Evaluation of accuracy of thermalhydraulic code calculations," Journal Energia Nucleare, vol. 7, no. 2, pp. 5-16, 1990.

[22] N. Aksan, F. D’Auria, H. Glaeser, R. Pochard, C. Richards, and A. Sjoberg, "Separate effects test matrix for thermal-hydraulic code validation Vol. I: phenomena characterisation and selection of facilities and tests," OECD/GD(94)82, Paris, France, July 1994.

[23] N. Aksan, F. D’Auria, H. Glaeser, R. Pochard, C. Richards, and A. Sjoberg, "Separate effects test matrix for thermal-hydraulic code validation Vol. II: facilities and experiment characteristics," OECD/GD(94)83, Paris, France, July 1994. 

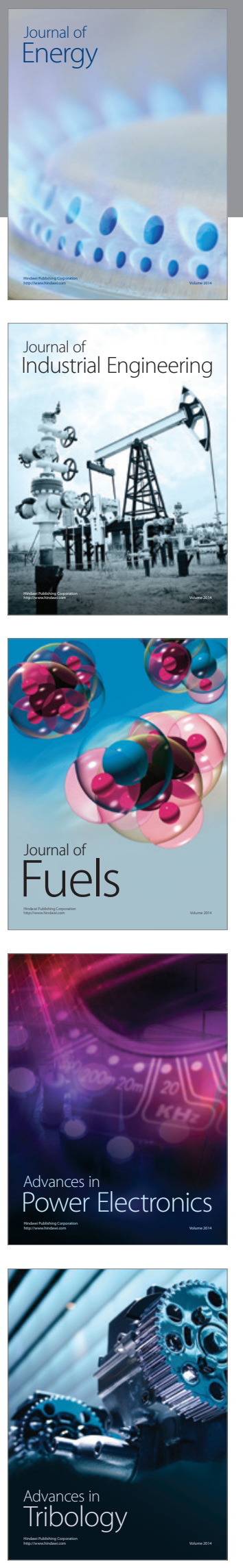
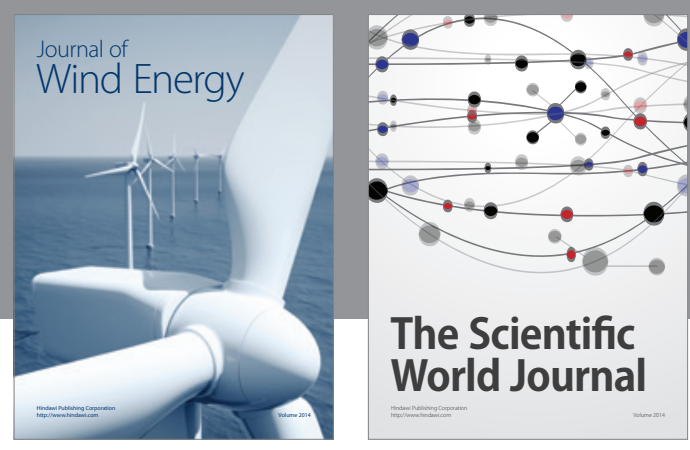

The Scientific World Journal

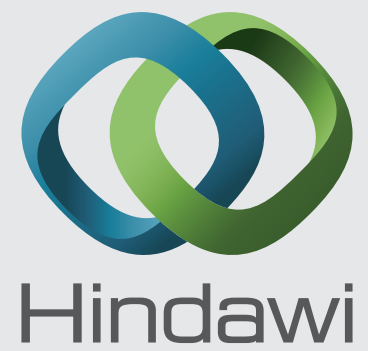

Submit your manuscripts at http://www.hindawi.com
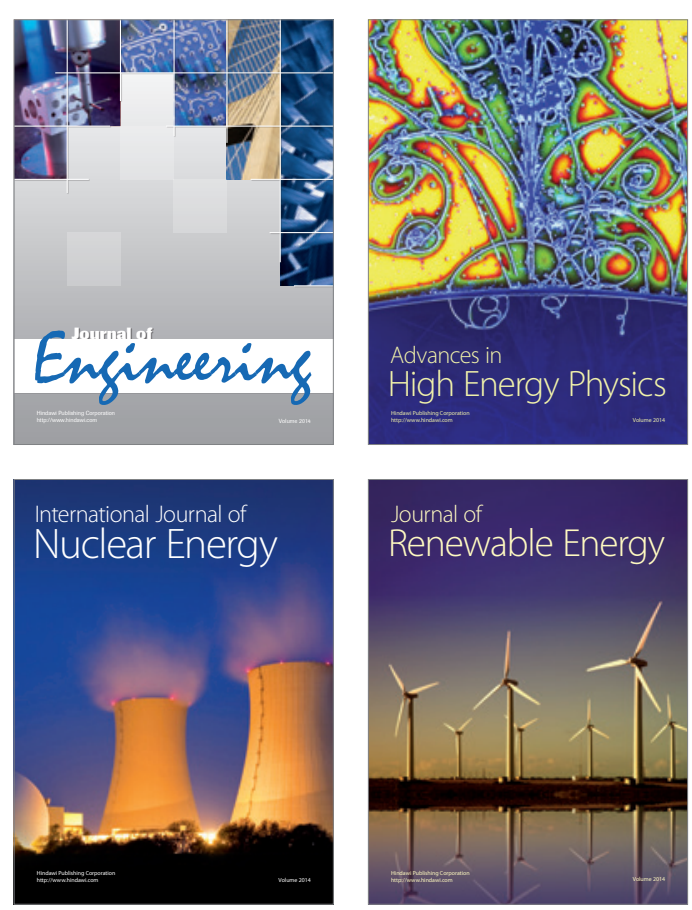

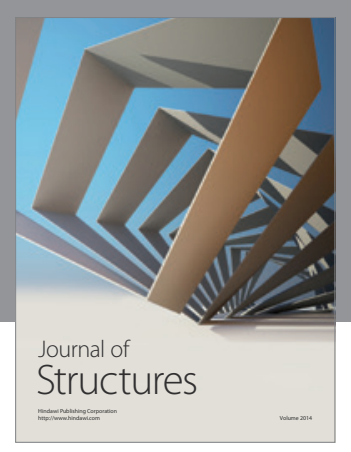

Rotating
Mechinery
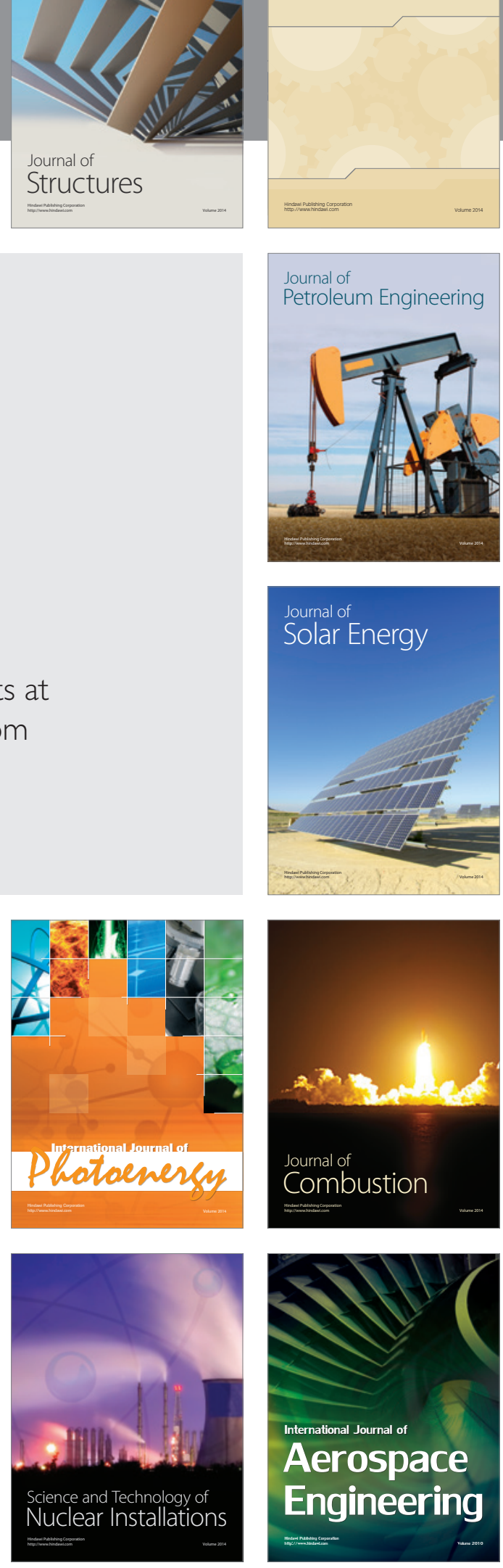